\title{
آمــون \\ أب رهبـان جبـل نيتريـا
}

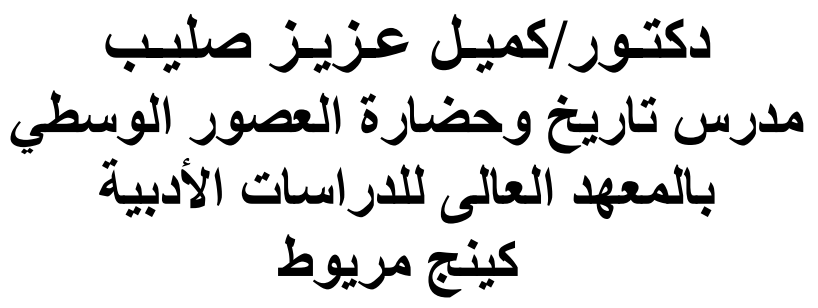

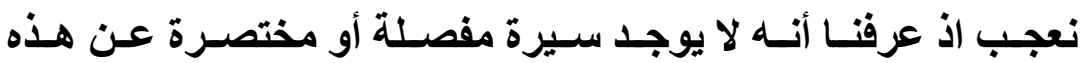

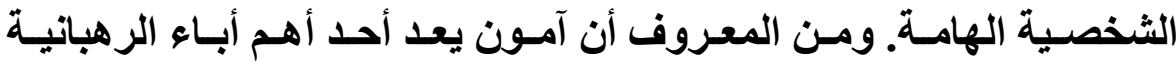

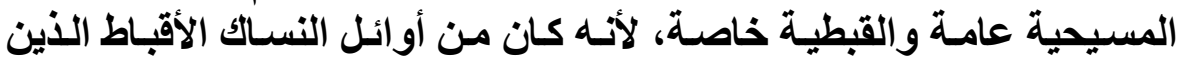

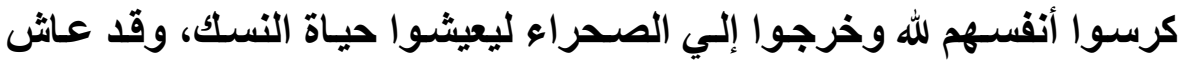

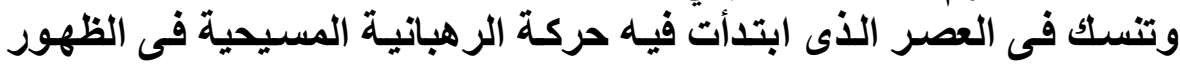

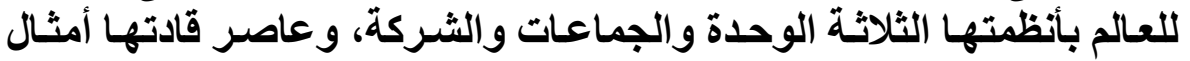

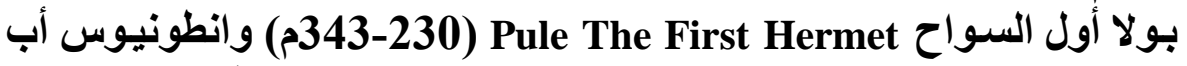
الرهبـان Antony The great (356-251م) مؤسسس نظــام الجماعـات 


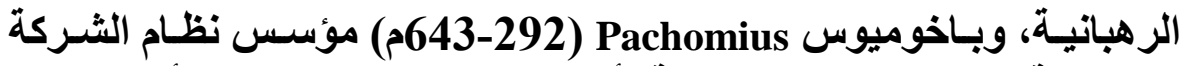

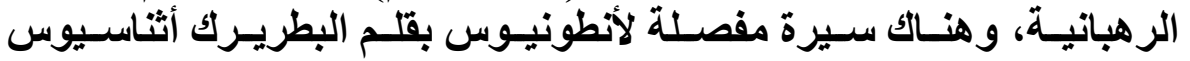

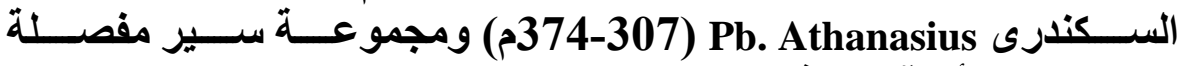

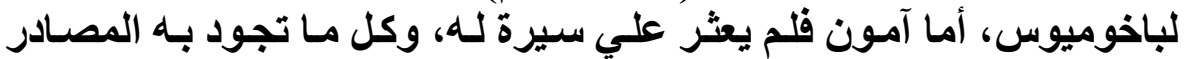

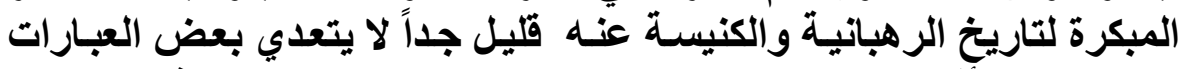

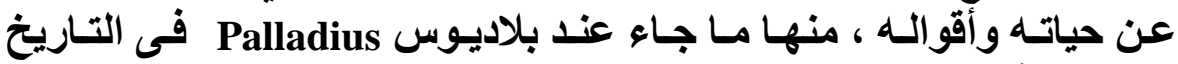

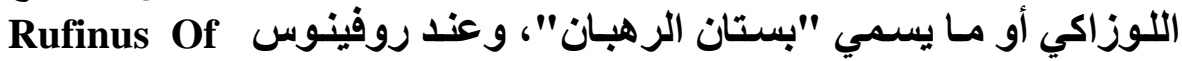
Aquileia

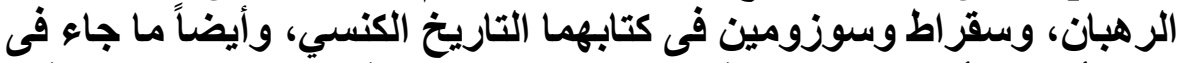

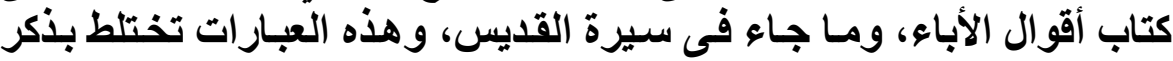

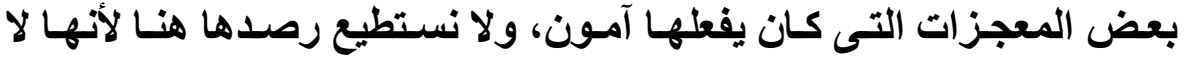

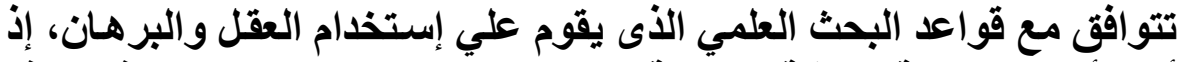

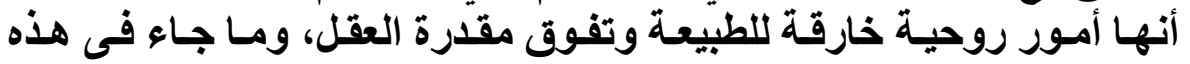

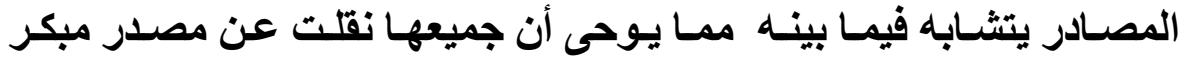

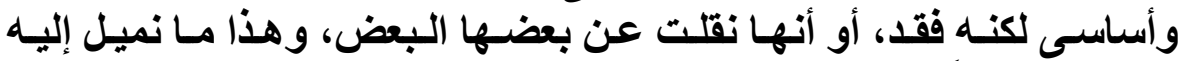

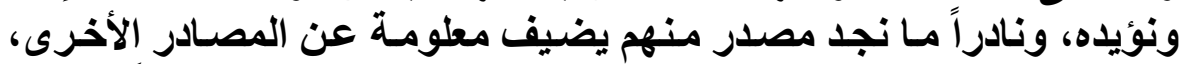

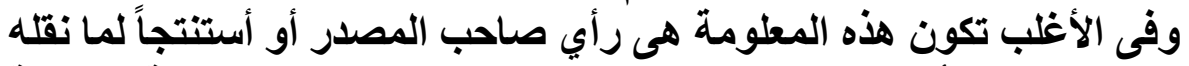

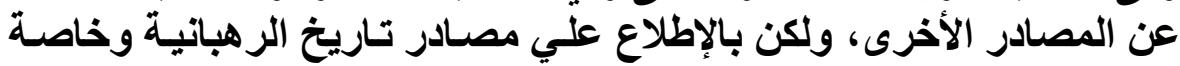

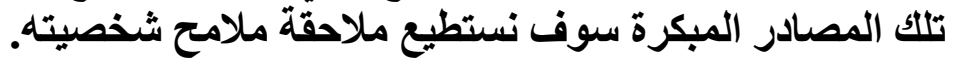

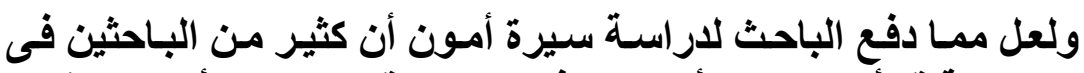

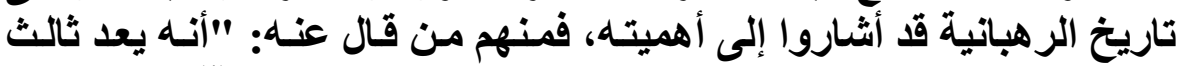

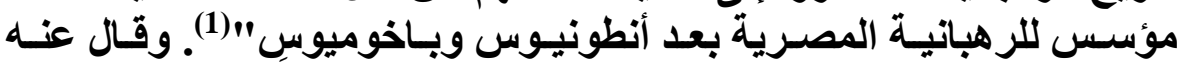
روبرت مـايرRobert meyer "أنسه يثبله أنطونيوس لأنسهة قام بنفس دوره

(1) هذا ما قالته الراهبة الباحثة بنديكتا وورد فى التعريف المختصر لها عن شخصية آمون فى كتاب أقوال الأباء.

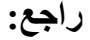

Sayings of The Desert Fathers, Trans. And Foreward by, Benedicta Ward. New York, 1975, p. 31. 


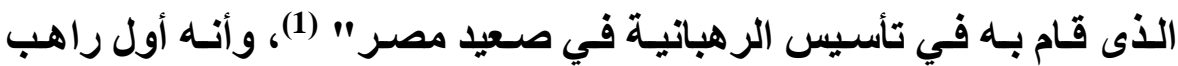

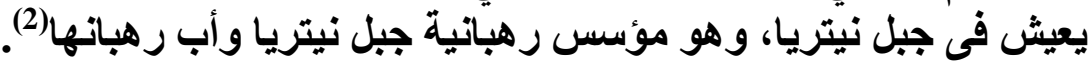

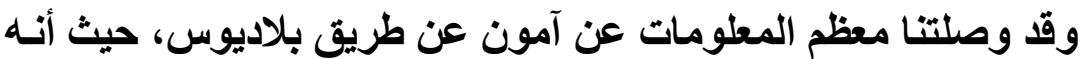

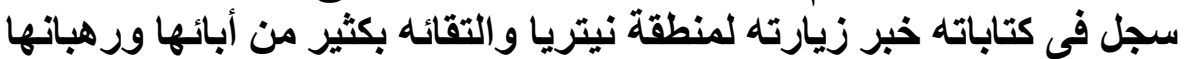

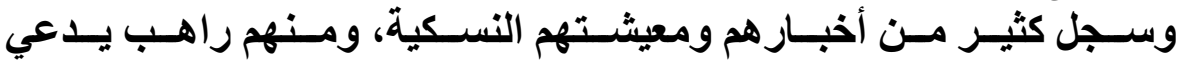

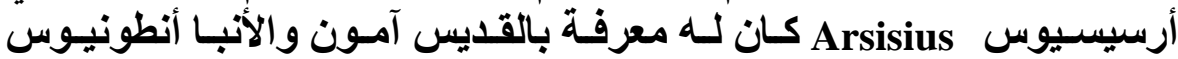

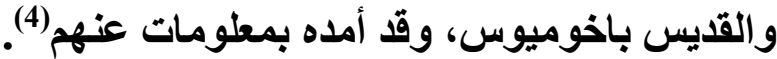

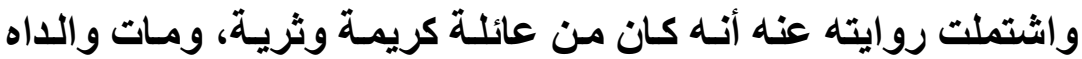

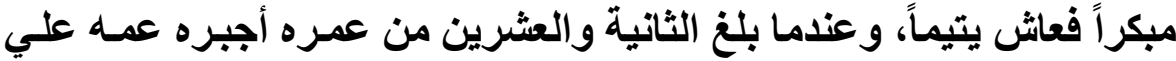

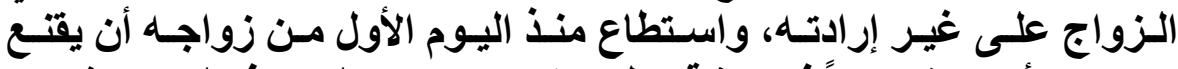

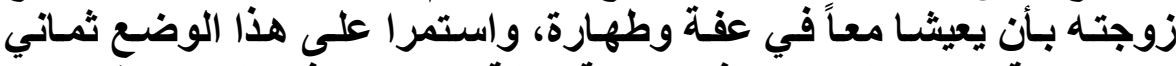

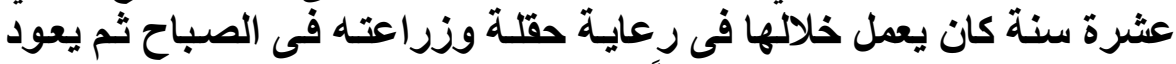

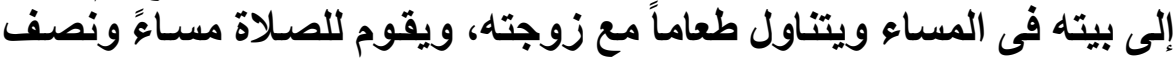

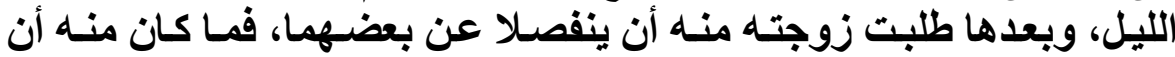

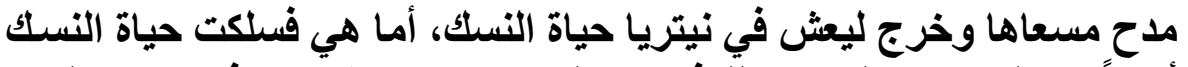

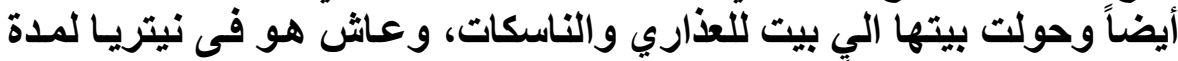

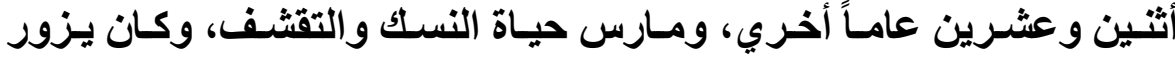

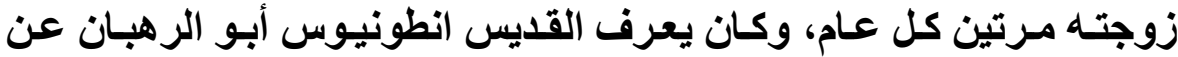

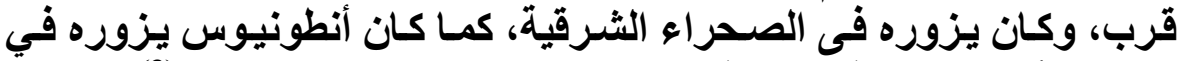

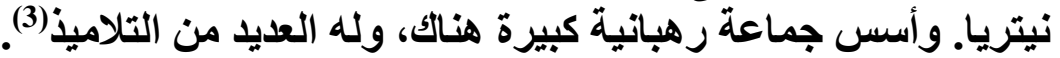

${ }^{(2)}$ Palladius, The Lausiac Histery, Trans. And Annot. By Robert T. Meyer. London. 1965, p. 175, Not. 89.

${ }^{(3)}$ Pall., Op. Cit, Ch. 8.; Rufinus, Lives of the Desert Fathers , trans.by, Norman Russell,Introduction by Sister Benedicta,in Monastic Studies Series 4,U.S.A, 1981,Ch. 22.; H.G. Evelyn White, The Monasteries Of The Wadi n Natrun 3 vol NewYork, 1931-1933. Vol, II, p. 47;

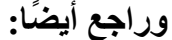

$$
\begin{aligned}
& \text { متي المسكين، الرهبانية القبطية عن القديس أبوا مقار، الطبعة الثالثة، الإسكنرية، دار مجلة }
\end{aligned}
$$

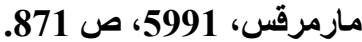

(4) Pall., Op. Cit, Ch. 7.

${ }^{(1)}$ Pall. Op. Cit., Ch. 8. 


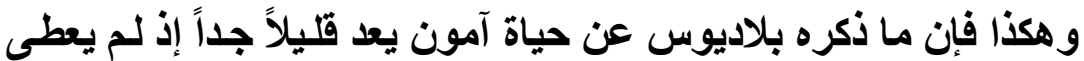

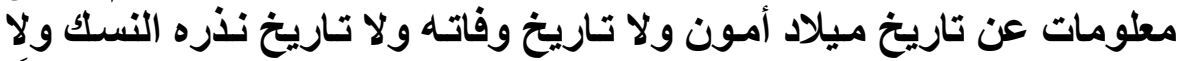

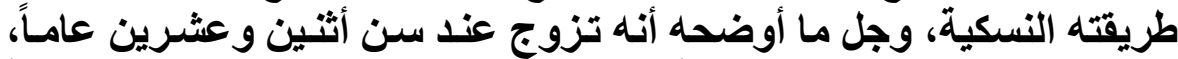

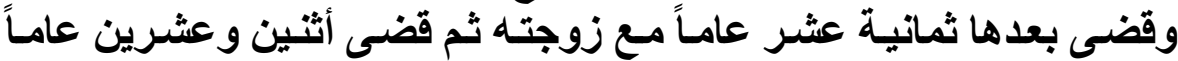

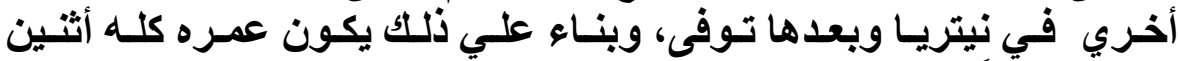

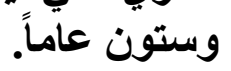

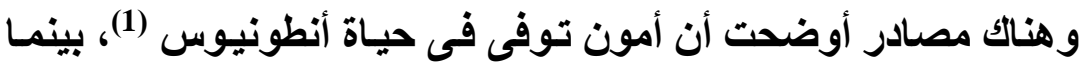

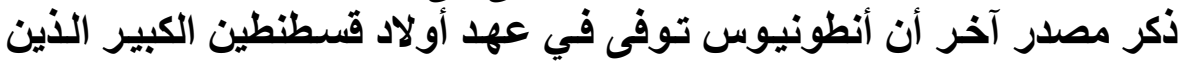

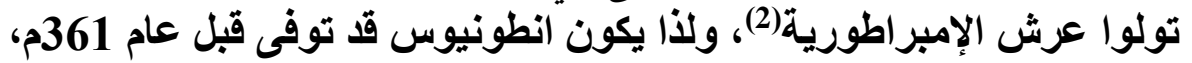

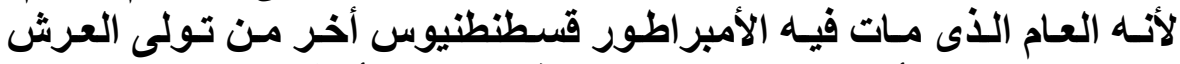

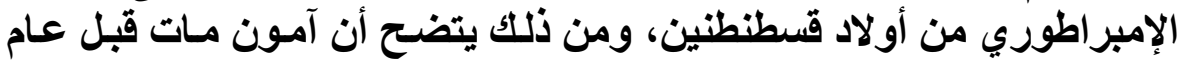
361

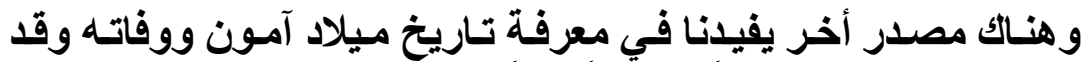

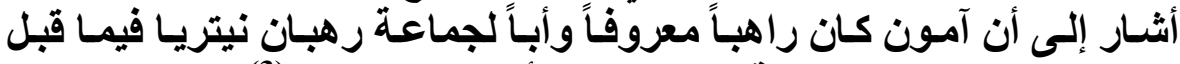

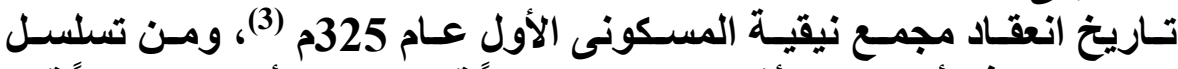

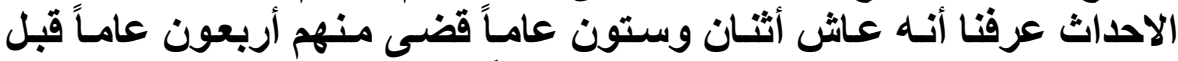

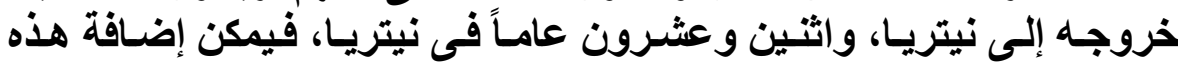

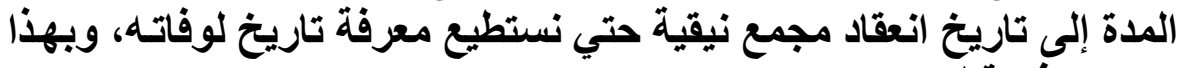

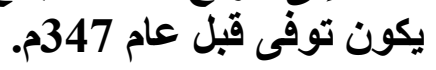

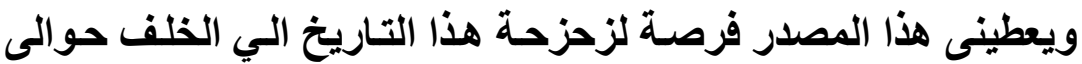
عشرة سنوات أخري، ولهذا نتفق مع مؤرخى الرهبانية في رأيهم ان آمسون

Rufinus, , Lives of the Desert Fathers, Ch. 22.

(2) Asanathus, The Life of S.Antony, Trans. With Not.byArchibald Robertson, In: Nicene And Post Nicene Fathers,ed. By Philip Schaff And Henry Wace, New York, 1994, ch 60.;Sozomenus,History Of The church, trans.by,Chester D.Hartranft, in (N.P.N.F.) $2^{\text {nd }}$ ser., Vol. 1.Book, 4, Ch., 23.; Rufinus , Lives of the Desert Fathers, Ch. 22.

(3) Jerom, The Illusterus Men, Trans. With Introd. And Not. by, Ernest cushing Richardson,In(N.P.N.F.) $2^{\text {nd }}$ ser.vol.3,Ch, 88.

${ }^{(1)}$ Soz., Op. Cit., Book, 4, Ch. 23. (2) - متى المسكين: الرهبانية القبطية، ص178. 
ولا حوالي 275م، وتزوج عام237مجام، وأعتزل العالم فى نيتريـا عام 315م،

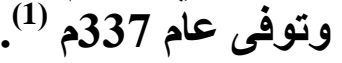

أما بالنسبة إلى المكان الذى ولد فيه أمون فنجد أحد المصدادر القبطية

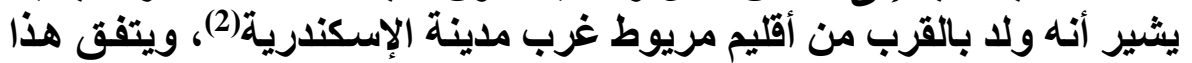

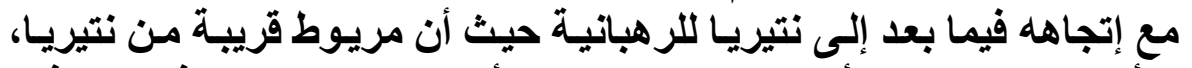

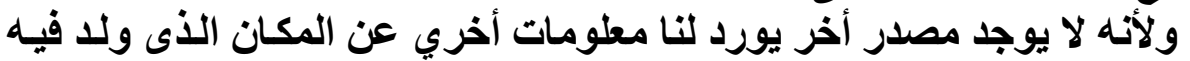
أمون فأنتا نتفق مع ما أورده هذا المصدر.

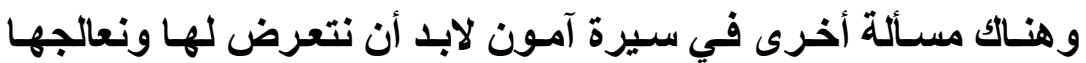

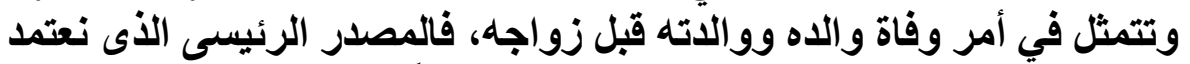

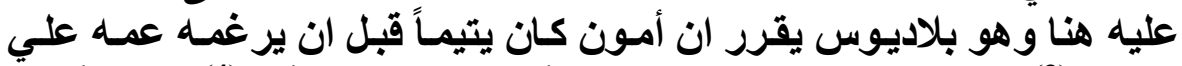

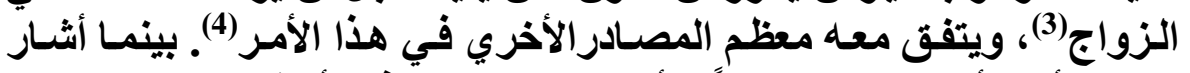

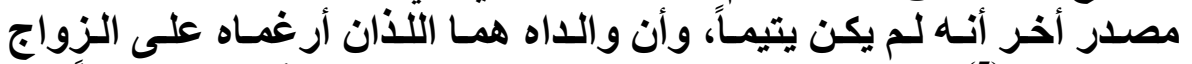

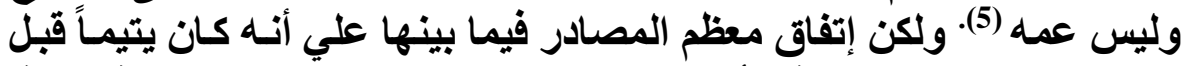

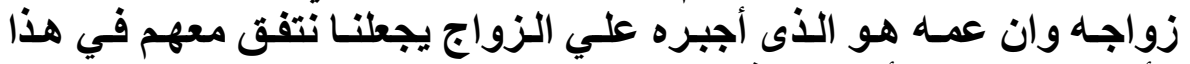
الأمر، ولا نقبل ما أتي به هذا التها المصدر التئفرد.

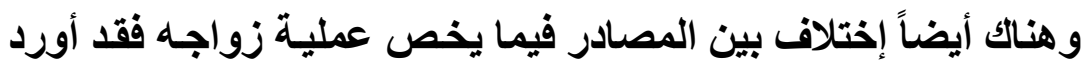

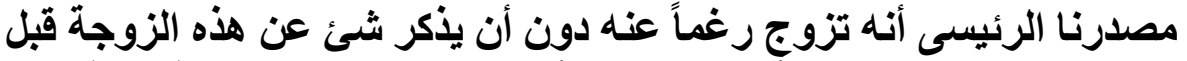
الزواج، لكن هناك مصدر أثنار بوضوح أنها كانت تنتمى إلى عائلة غنية مثلكه

(3) السنكسار القبطي، اليوم العثرين من شهر بثنس المبارك.

(4) Pall. Op. Cit., Ch. 8.

${ }^{(5)}$ Soz., Op. Cit., Book. 4, Ch. 23.

السنكسار القبطي: اليوم العشرين من شهر بثنس.

${ }^{(6)}$ Rufinus, Lives of the Desert Fathers, Ch. 22.

(1) Rufinus, Lives of the Desert Fathers, Ch. 22.

(2) السنكسار القبطي: اليوم العشرين من شهر بثنس. 


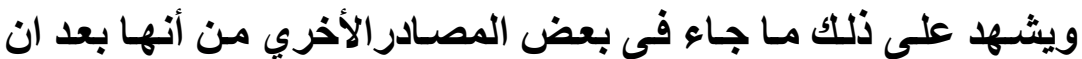

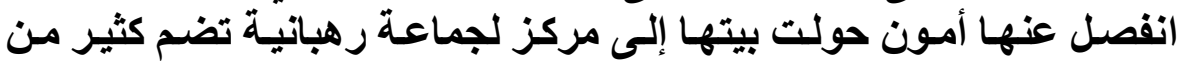

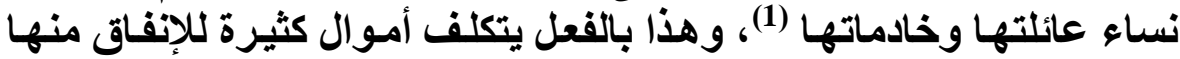
علي تلبية الإحتياجات المعيشية لهن، وهو الأمر الذى لا تستطيع سيدة فقيرة

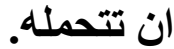

وكما تطالعنا المصادر أن زوجة أمون لم تكن غنية في الماديات فقط بل فيل

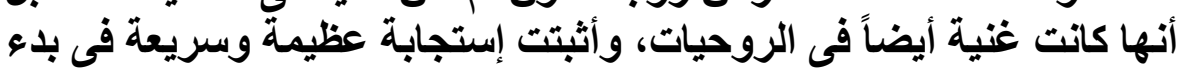

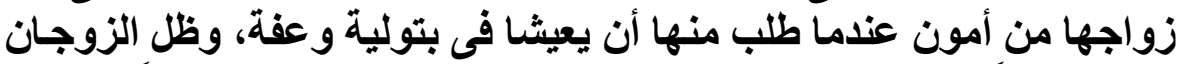

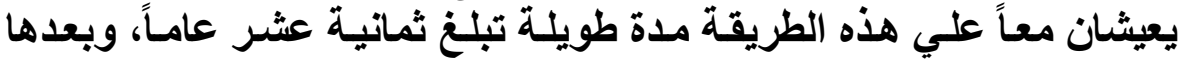

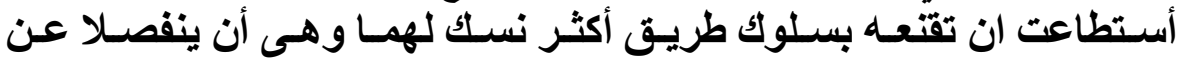

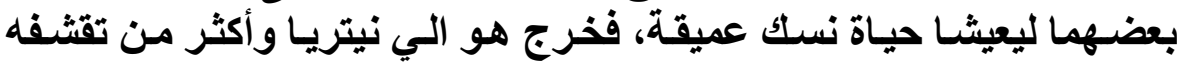

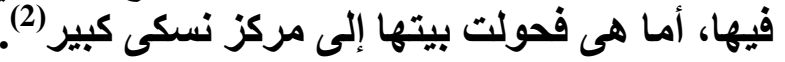

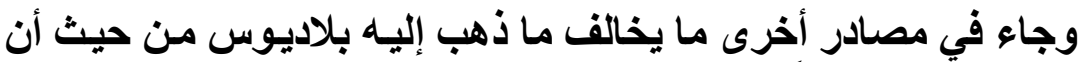

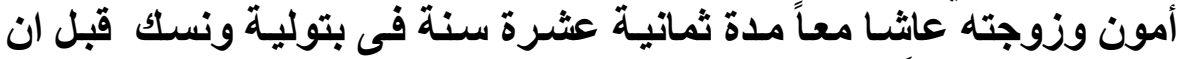

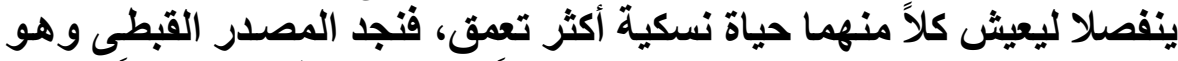

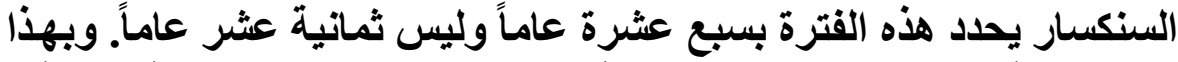

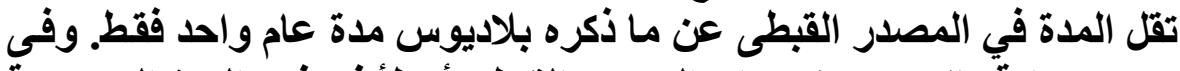

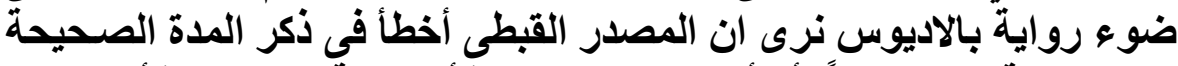

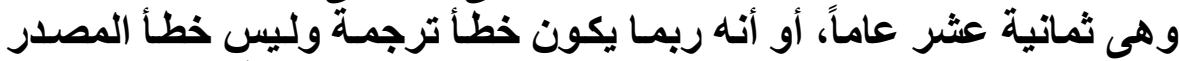

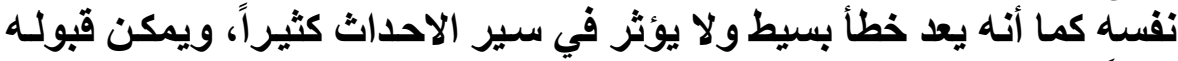
نظراً لتقاربه مع المدة التى حددها بلاديوس.

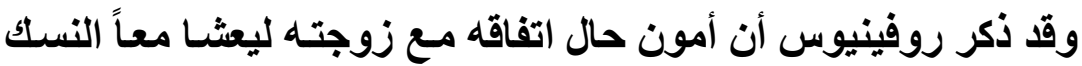

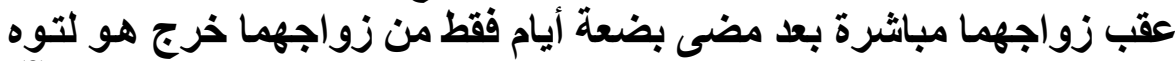

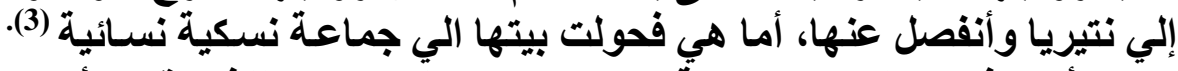

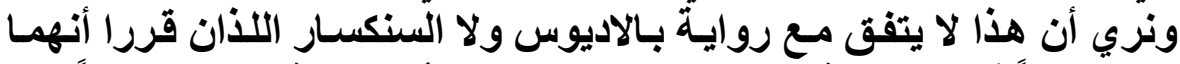

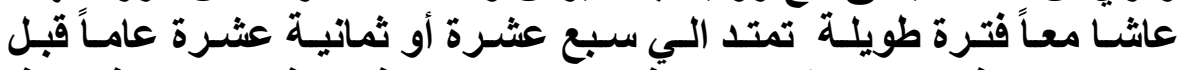

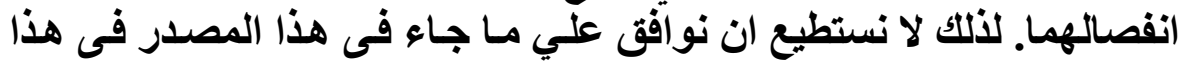

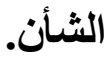

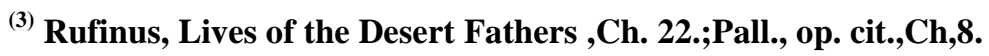

(4) Rufinus, Lives of the Desert Fathers, ch. 22.; Pall. op. cit., Ch. 8.; Soz. op. cit., Book, 4, Ch., 23.

(1) Rufinus, Lives of the Desert Fathers, Ch. 22. 


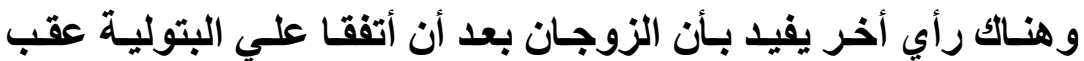

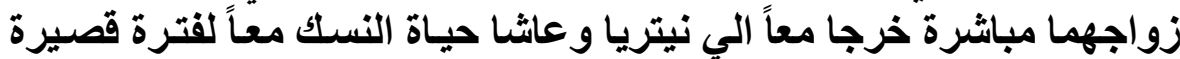

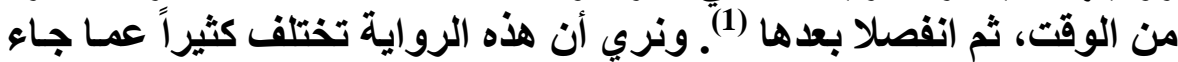

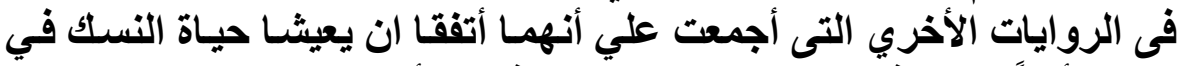

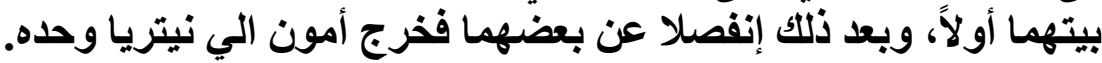

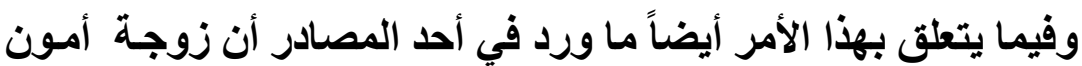

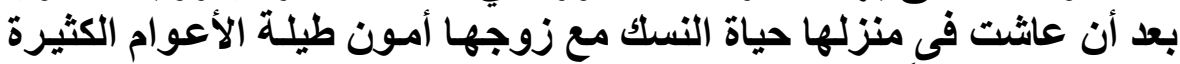

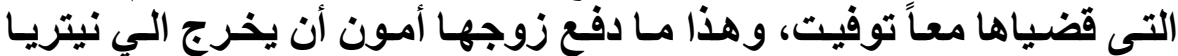

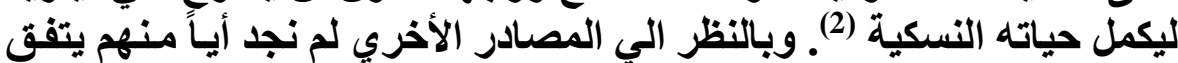

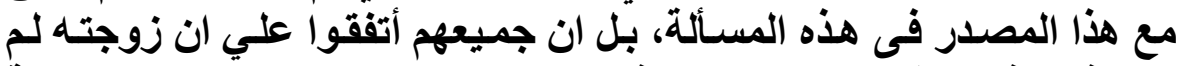

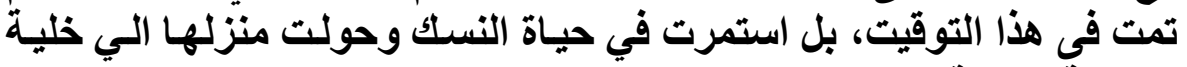
رهبانية نسائية.

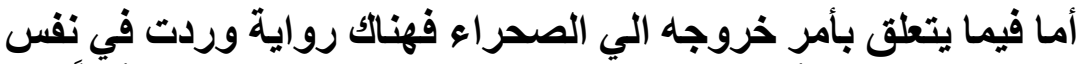

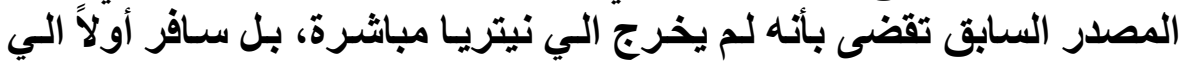

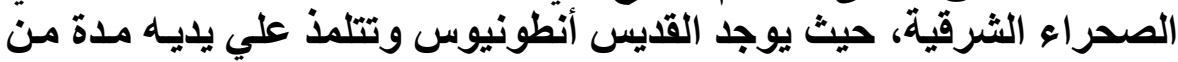

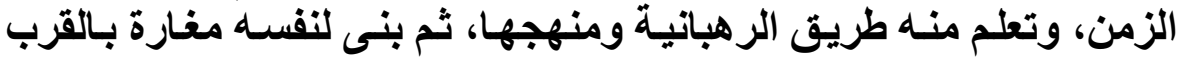

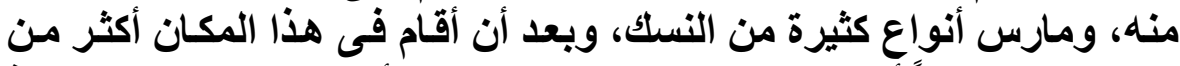

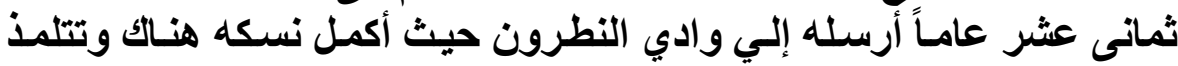

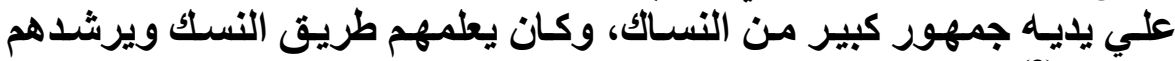

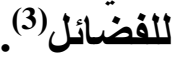

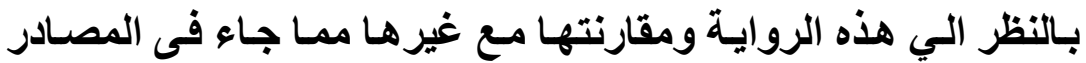

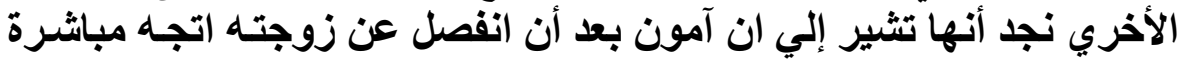

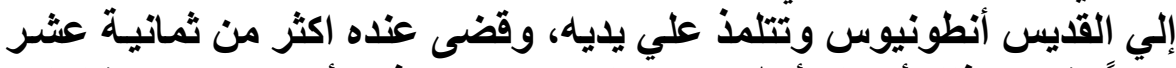

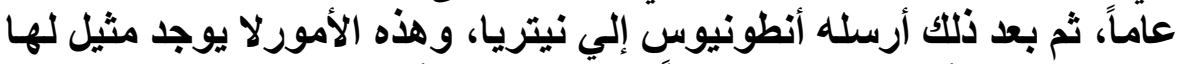

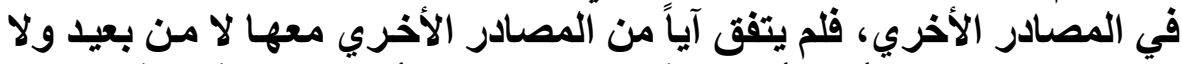

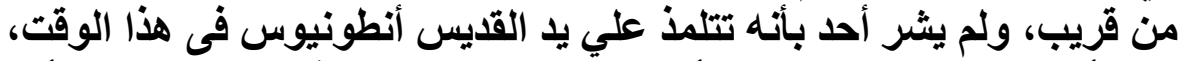

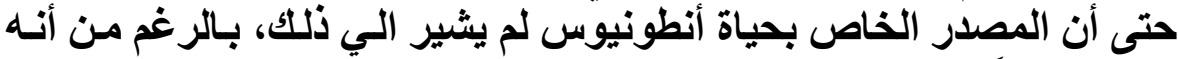

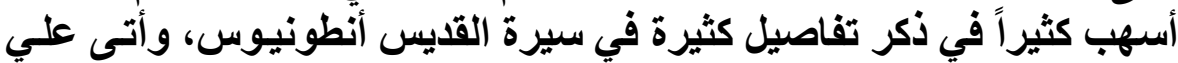

(2) Socrates, History Of The church trans.by,C Giffert, in( N.P.N.F) $2^{\text {nd }}$ ser.,Vol.2.Book, 4, Ch. 23.

$$
\begin{aligned}
& \text { (3) السنكسار القبطى: اليوم العشرين شهر بثنس. } \\
& \text { (1) نفس المصدر السابق. }
\end{aligned}
$$


ذكر كثير من تلاميذه أيضاً كما أنه أفرد فصلاً عن أمون ولم يثير الـي شئ

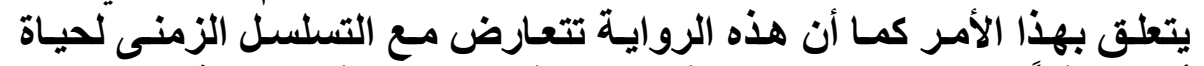

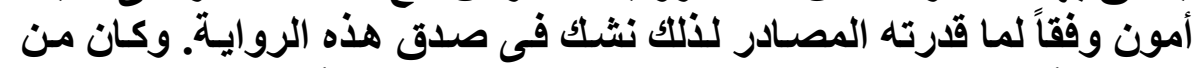

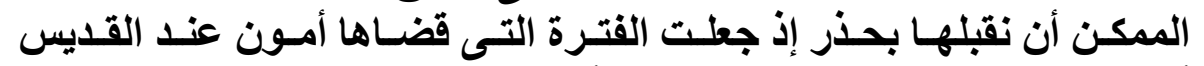
أنطونيوس فترة قصيرة لان اتتعدي العام أو العامين.

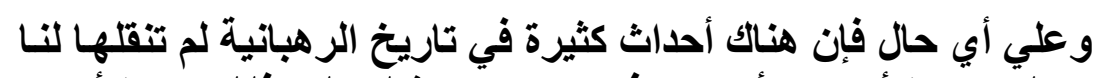

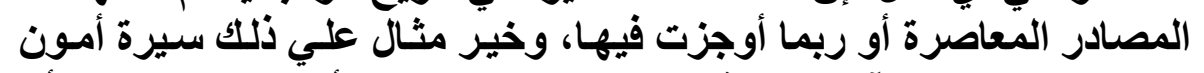

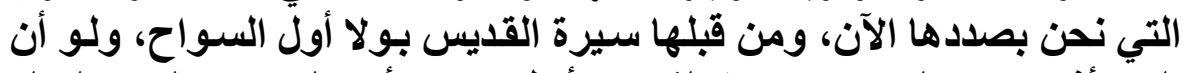

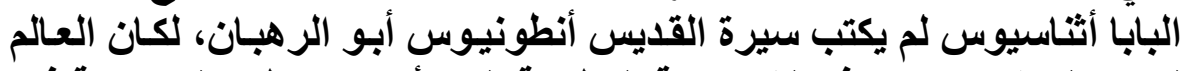

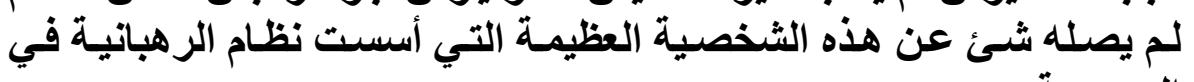

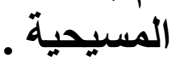

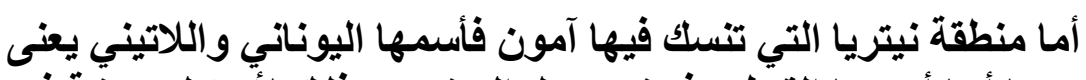

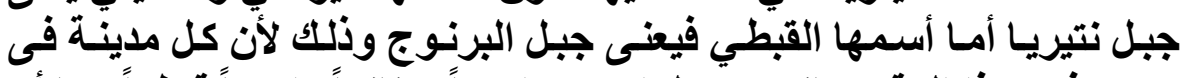

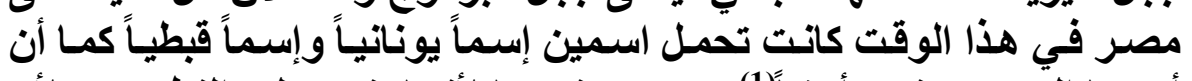

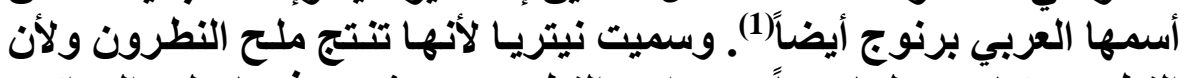

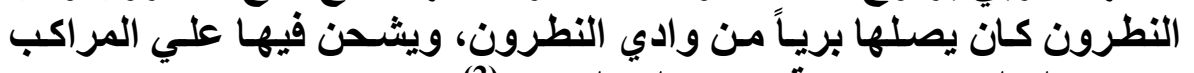

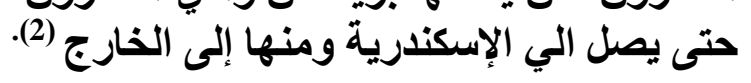

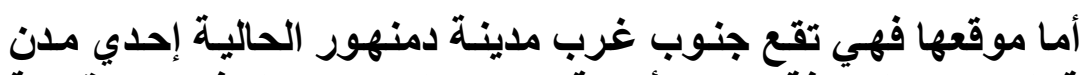

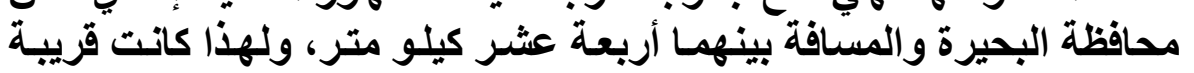

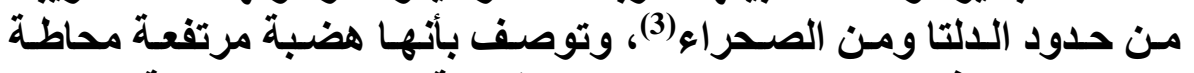

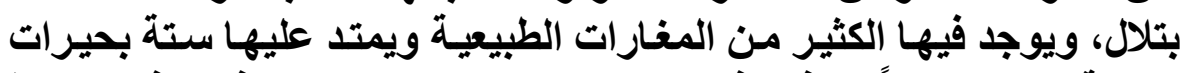

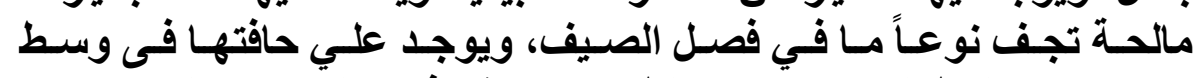

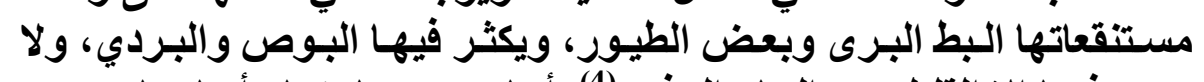

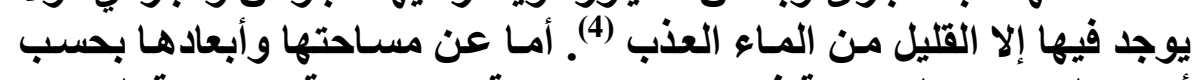

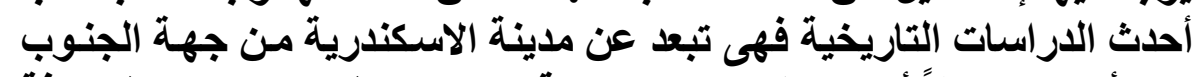

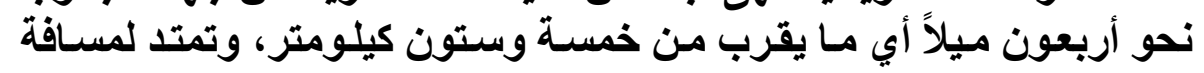

${ }^{(2)}$ Chitty,op.cit., p. 11, 12.

(1) متى المسكين: المرجع السابق، ص، 172 ـ

(3) محم رمزى، القاموس الجغرافى للبلاد المصرية، قسم 2، جزء 2.

(4) R. P. Paul Cheneau. D'Orleans, Les Saintes D'Egypte, Jersalem,1923,2 vol., Vol, 1, 121. 


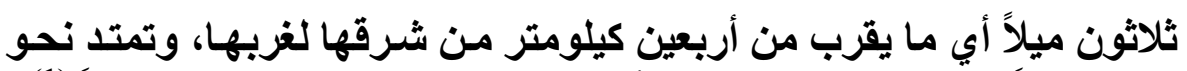

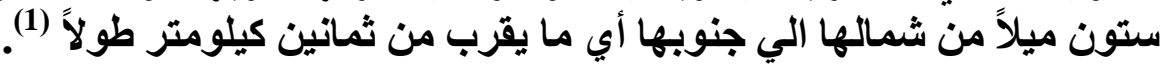

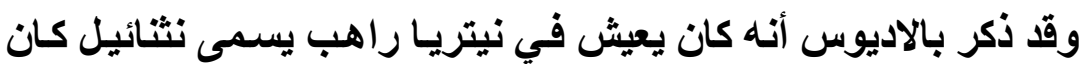

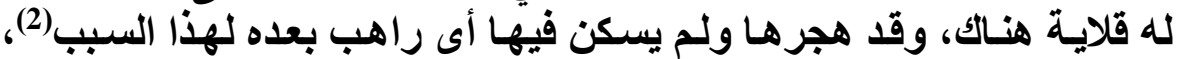

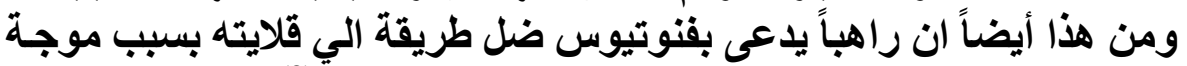

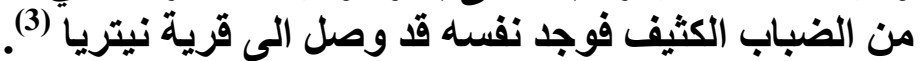

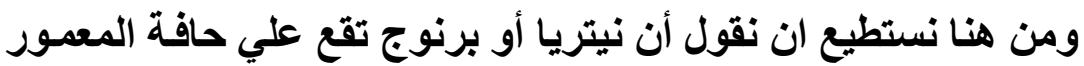

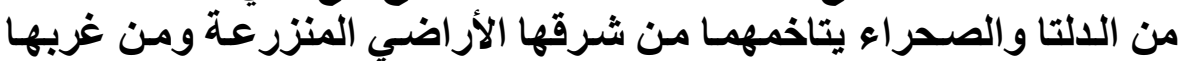

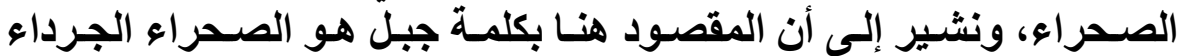

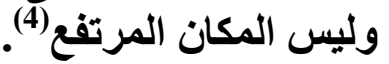

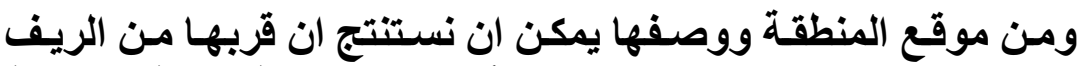

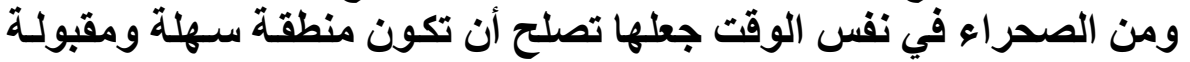

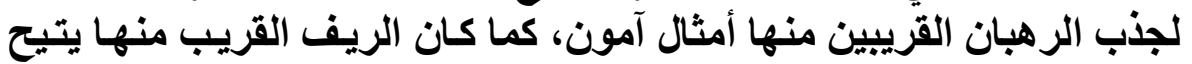

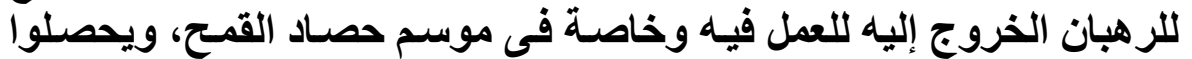

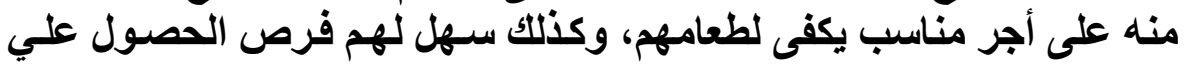

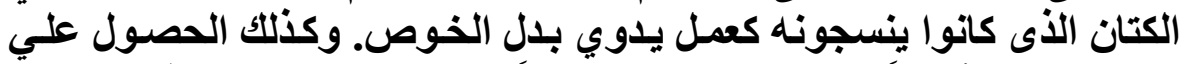

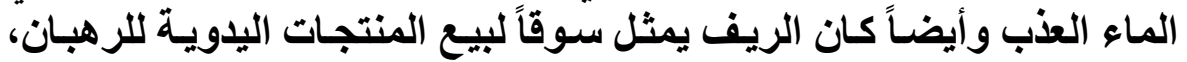

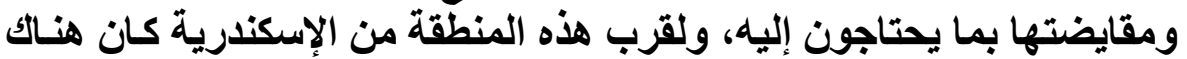

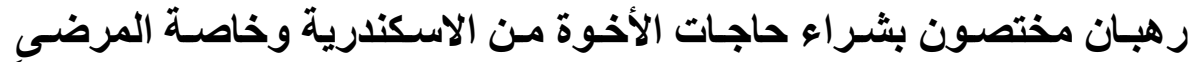

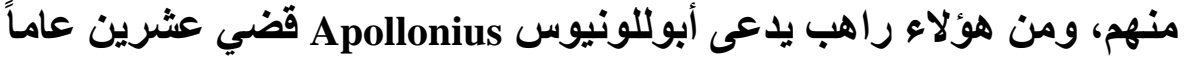

(5) Derwas, J.Chitty,The Desert ACity,Oxford,1966. p.12.; W.H. Mackean, Christianity Monasticism In Egypt To The Close Of Fourth Century.,London,1920.p. 81.; Patrich,j. Joseph, Sabas, Leader of Palestinian Monasticism, A Comparative Study in Eastern Monasticism, Fourth to Seventh Centuries, (Washington, 1995) p. 11, 12.;

${ }^{(1)}$ Pall. Op. Cit., Ch. 16.

(2) The Sayings of The Desert Fathers, Paphnutms, 1.

${ }^{(3)}$ Evelyn White. Op. Cit., p. 50., Chitty, op.cit., p. 11, 12.

متي المسكين: مرجع سابق، ص 372، 271 
في نيتريا وكان يسـافر بصفة دائمسة الى الإسكندرية لثراء حاجـات الرهبان

كمـا أن سطحها المرتفع واقترابها من الصحر اءع إضـافة إلي مغائرهـا

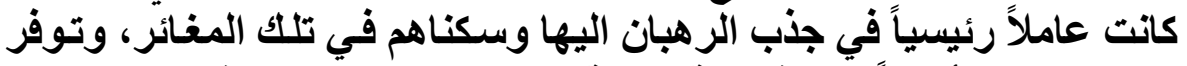

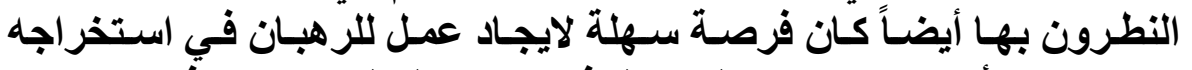

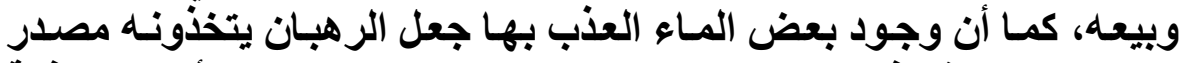

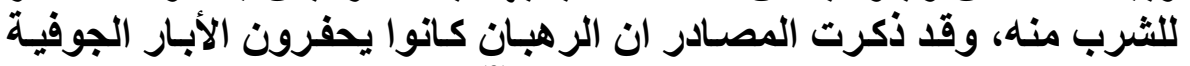

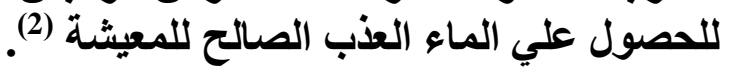

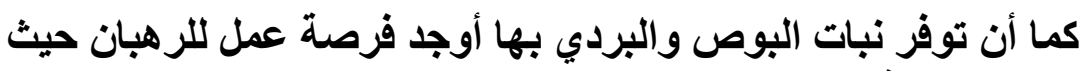

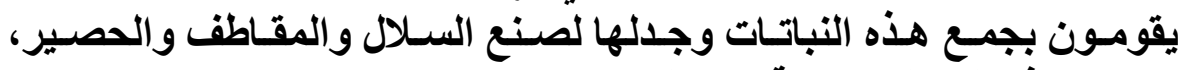

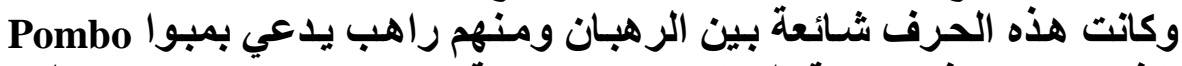

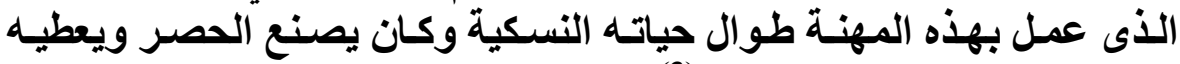

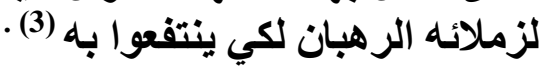

وهذا الأمر لا يختلف كثيراً عما كان آمون يقوم به في نيتريا، وبالنسبة التهبة

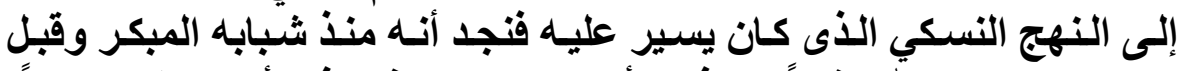

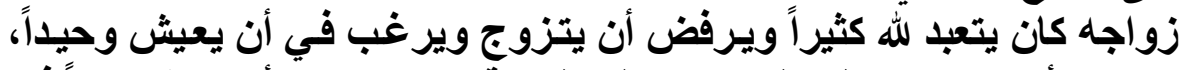

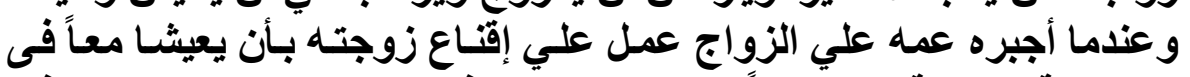

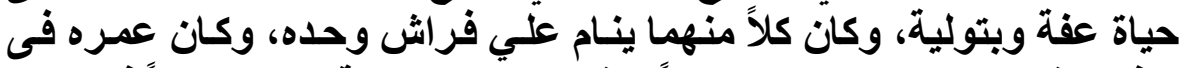

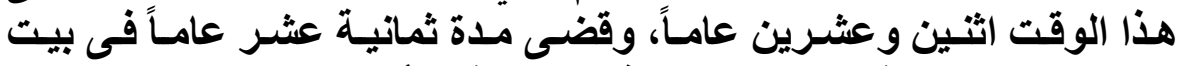

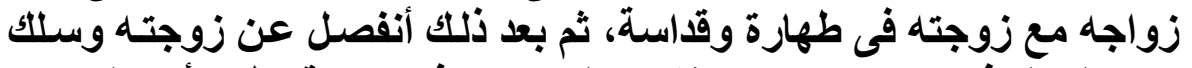

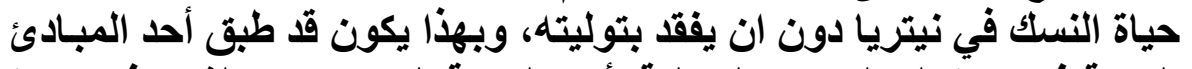

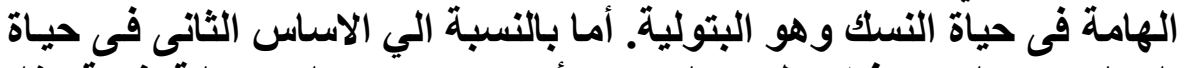

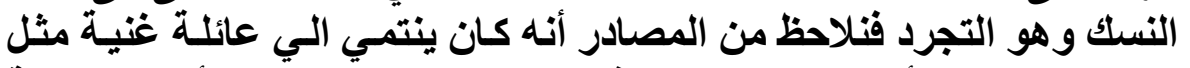

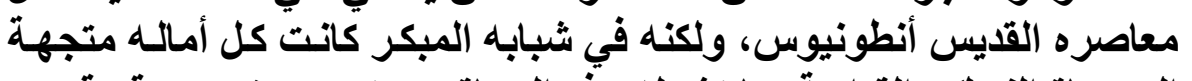

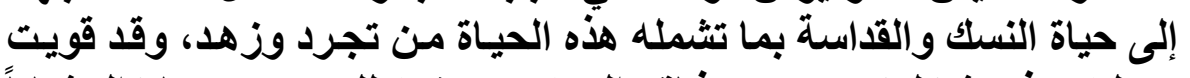

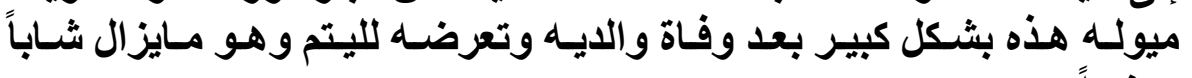

صغيراً.
(4) Pall. Op. Cit., Ch. 13.
${ }^{(1)}$ Ibid., Ch. 18.

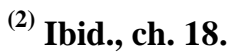




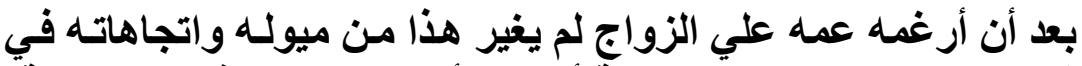

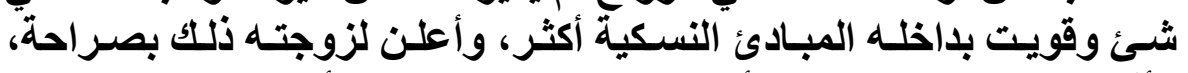

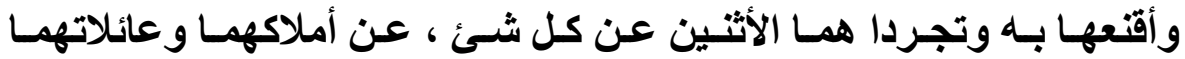

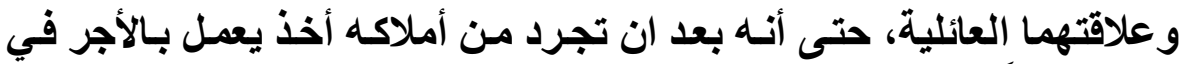

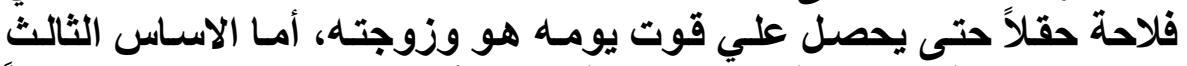

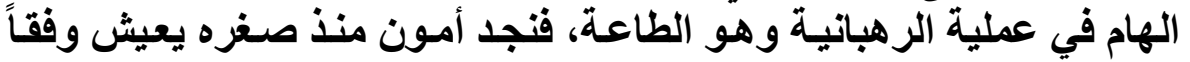

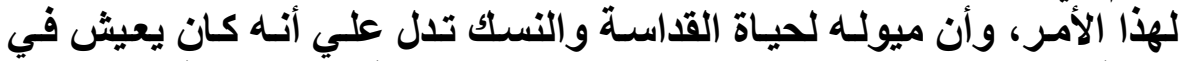

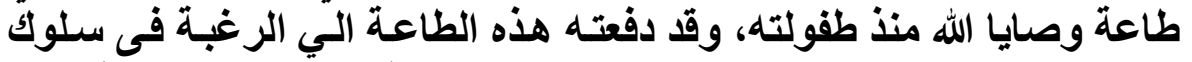

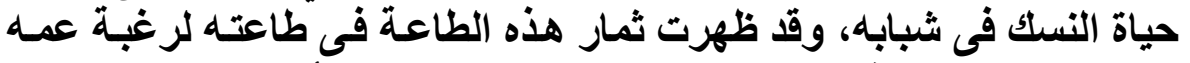

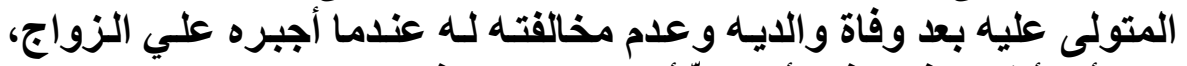

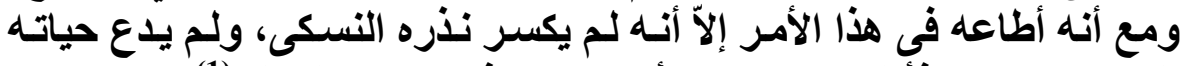

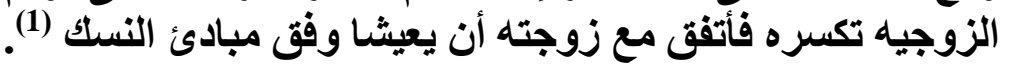

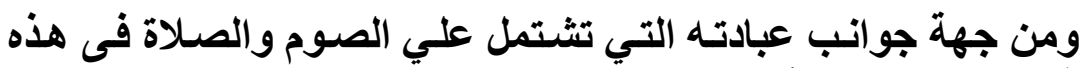

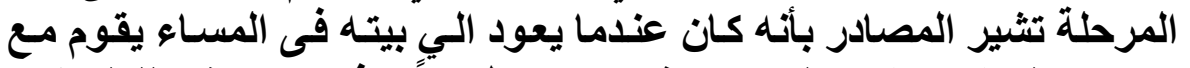

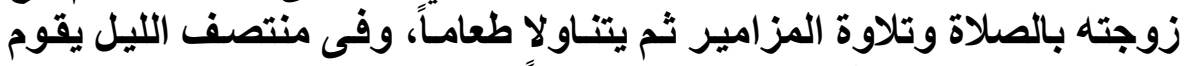

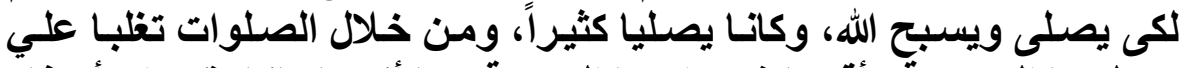

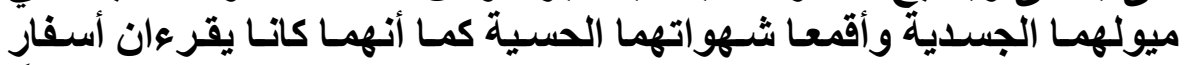

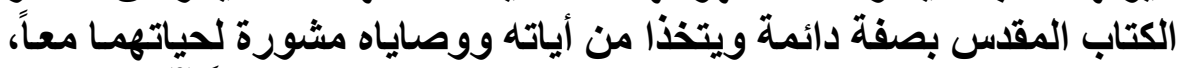

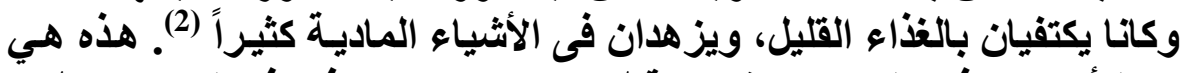

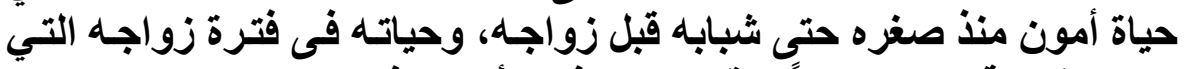

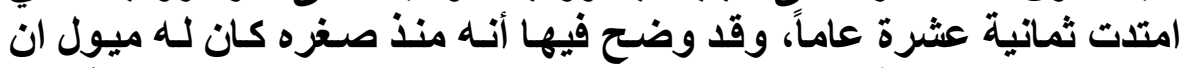

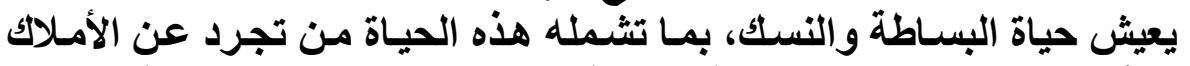

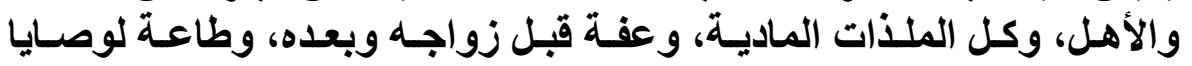

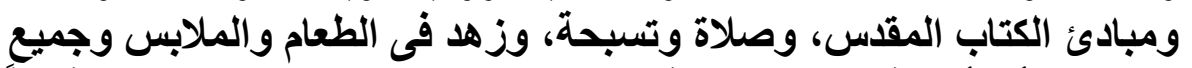

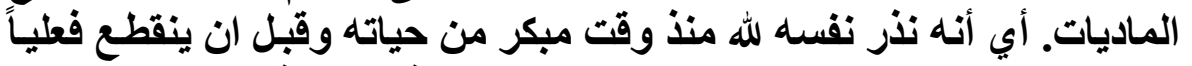
عن العالم ويتجه الي نيتريا ليعيش حياة نسك كاملة وعميقة.

(1) Pall. Op. Cit., Ch. 8, Rufinus, Lives of the Desert Fathers, Ch. 22.; Soz., Op. Cit., Ch. 23.,

(2) Pall,Op.Cit.,Ch. 8; Rufinus, Lives of the Desert Fathers,Ch. 22. السنكسار القبطي: اليوم العشرون من شهر بشنس. السنكسار القبطي: اليوم العشرون من شهر بشنس. 


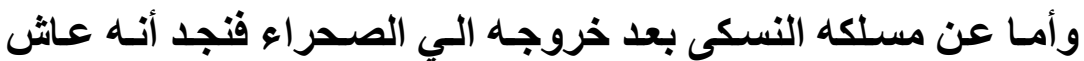

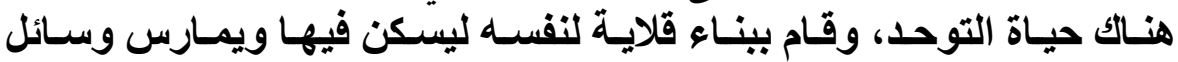

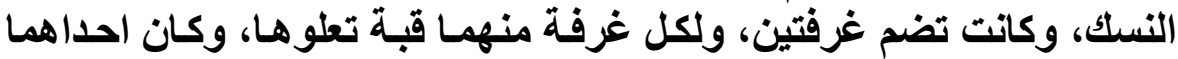

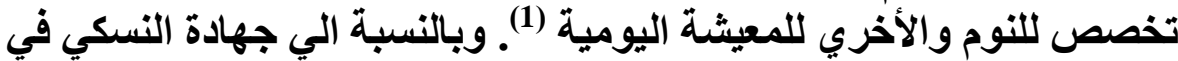

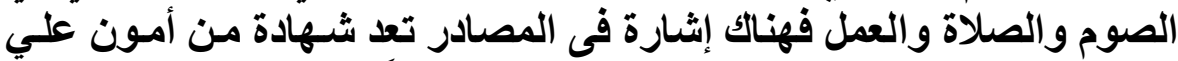

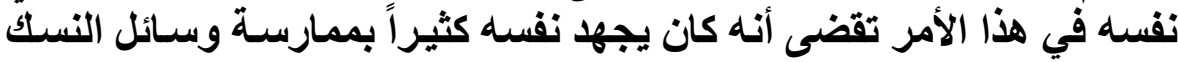

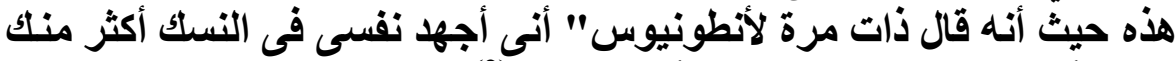

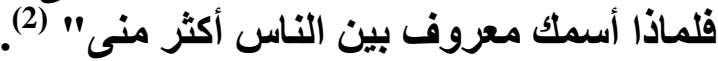

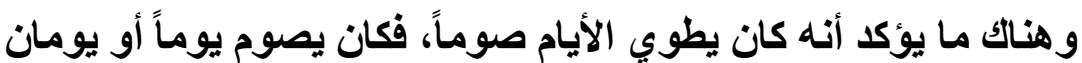

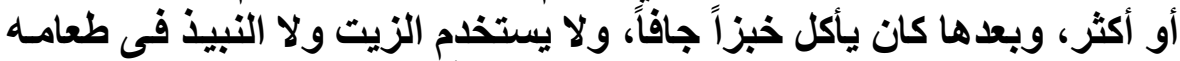

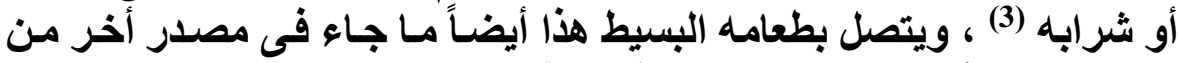

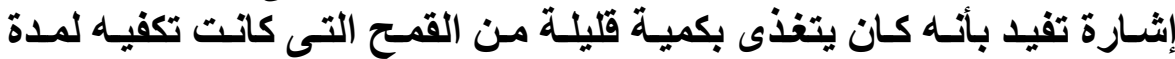

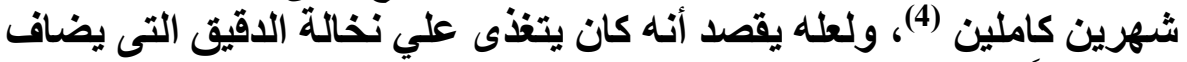
اليها قليلاً من الماء حتى تصبح عجينة لينة ويتناولها كما هي.

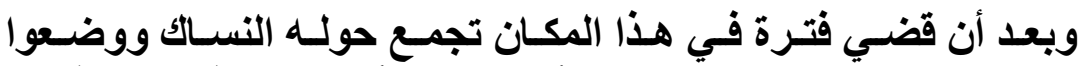

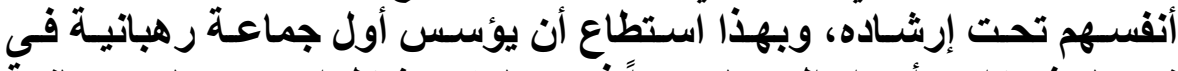

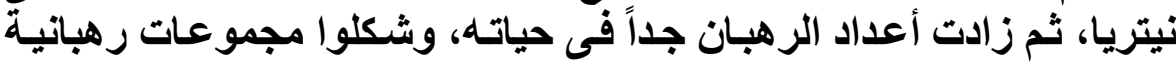

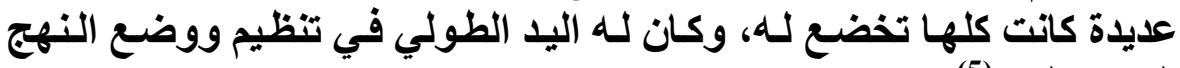

النسكي لهم (5)

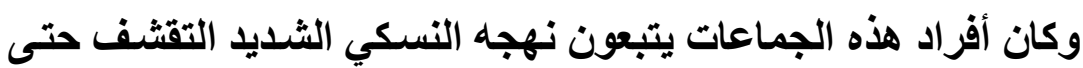

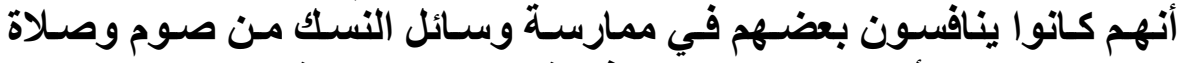

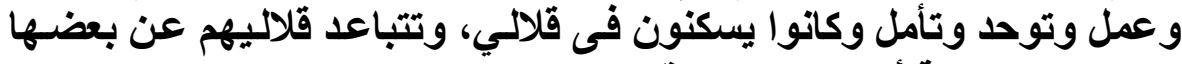

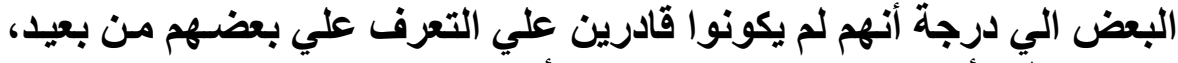

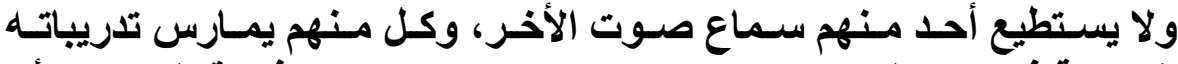

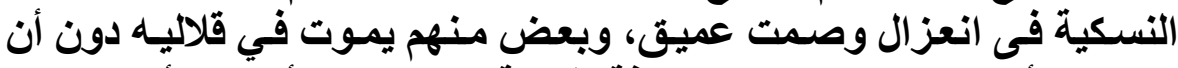

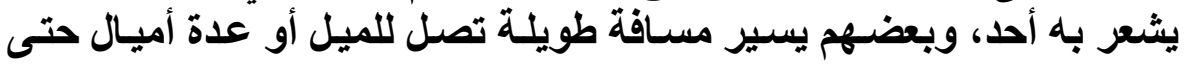
${ }^{(3)}$ Soz. Op. Cit., IV, 23.
(1) The Sayings of The Desent Fathers, Amoun of Nitria, 1.
${ }^{(2)}$ Soc. Op. Cit., 23.
(3) The Sayings of The Desent Fathers, Amoun of Nitria, 2.
(4) Rufinus, Lives of the Desert Fathers, Ch. 20, Soc, Op. Cit., ch. 23, Soz, Op.
Cit., ch, 23. 
يلتقى بأبيه الروحى، وكانوا يلتقون معاً مرة كل أسبوع في مساء يوم السبو السبت

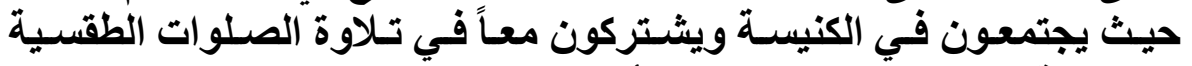

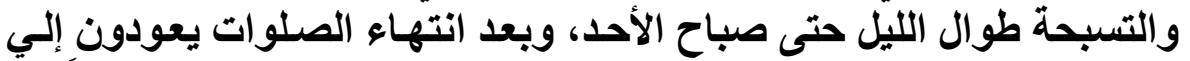

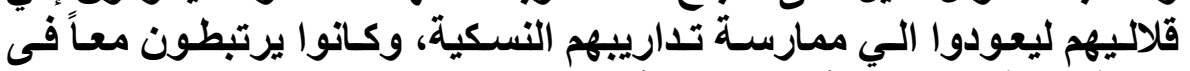

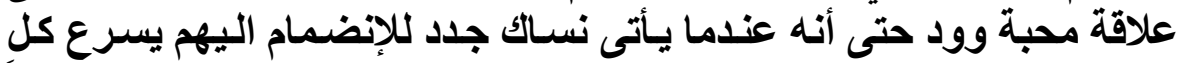

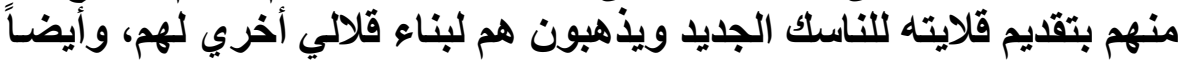

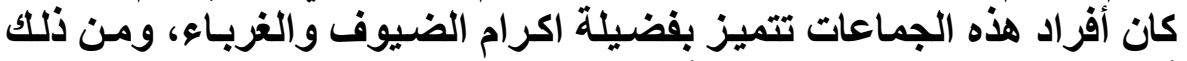

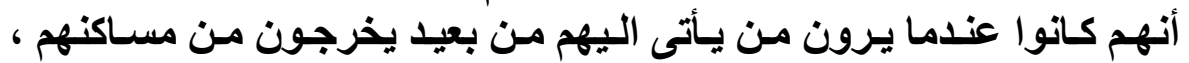

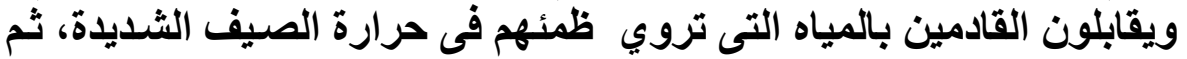

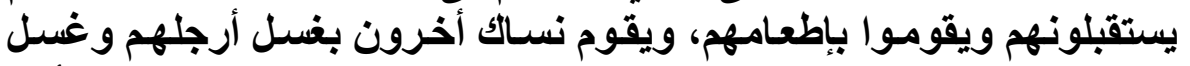

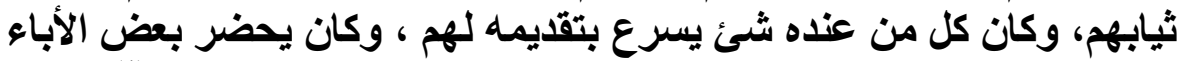

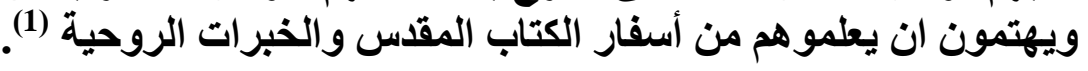

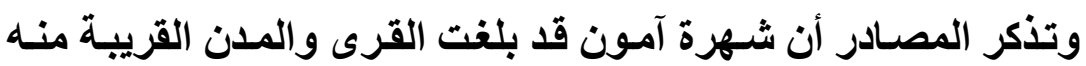

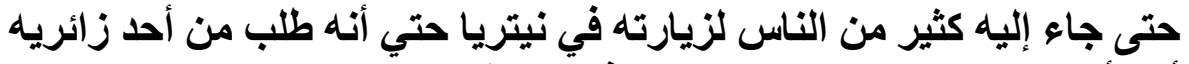

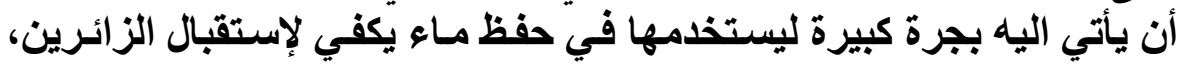

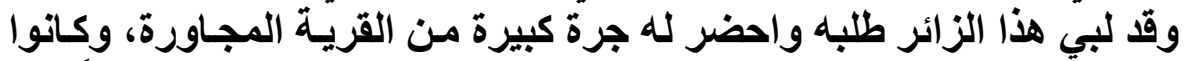

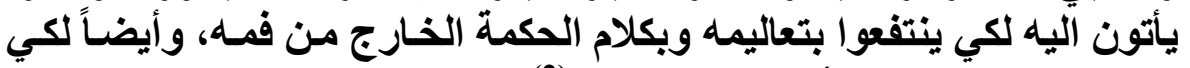
يطلبوا منه الصلاة من أجلهم ولمرضاهم (2).

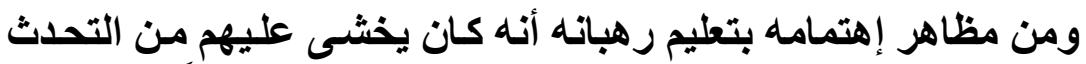

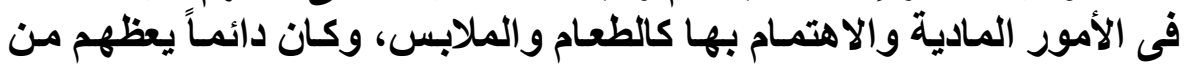

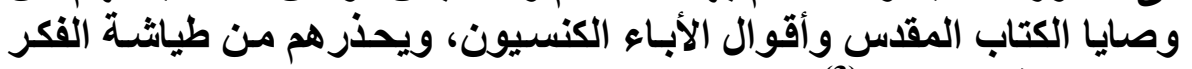
والسقوط في الخطايا (3).

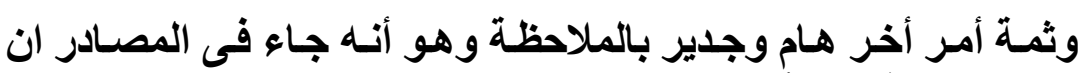

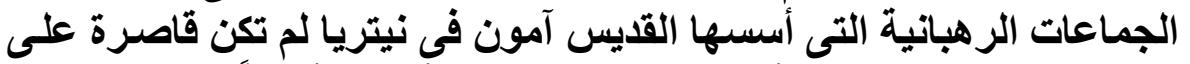

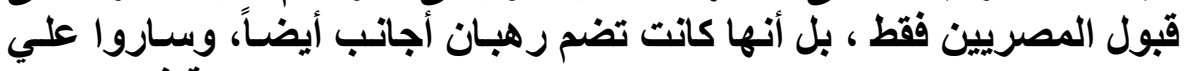

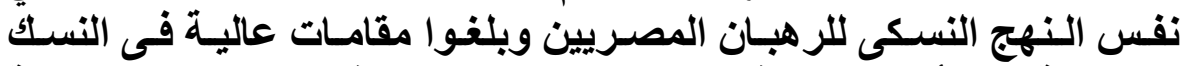

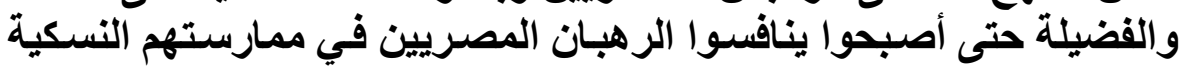

${ }^{(1)}$ Rufinus, Lives of the Desert Fathers, Ch. 22.

(2) Ibid.

(3) The Sayings of The Desert Fathers, Amoun of Nitria, 2, 3. 
(1) ويتضح من ذلتك ان الرهبانية منذ قيامها فى مصر سريعاً ما أنتشر خبرها فى العالم كله وجذبت شنصيات من كافة الأقطار للمشاركة فئها.

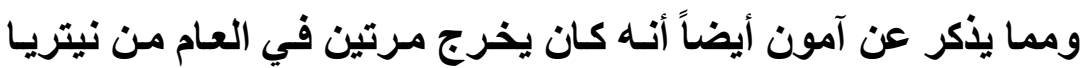

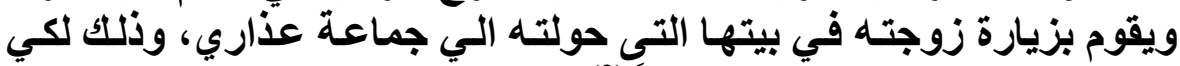

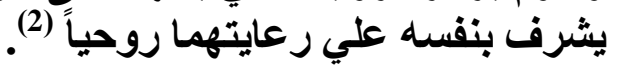

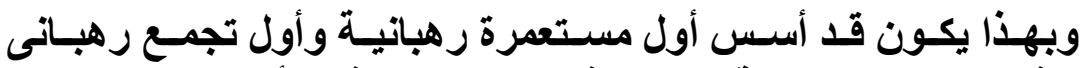

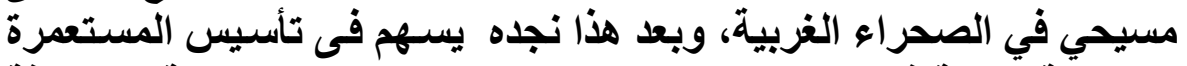

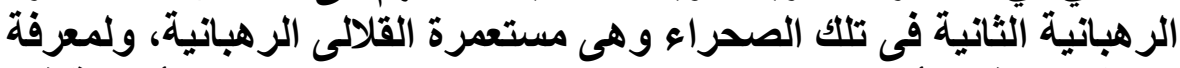

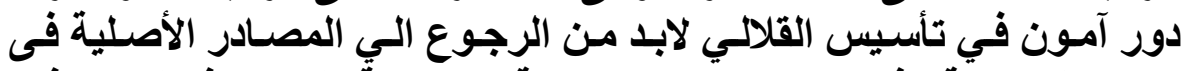

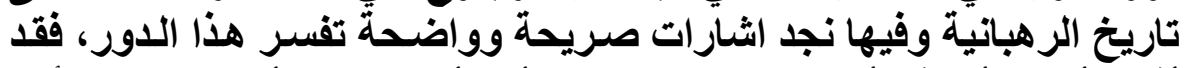

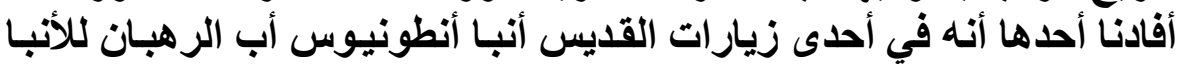

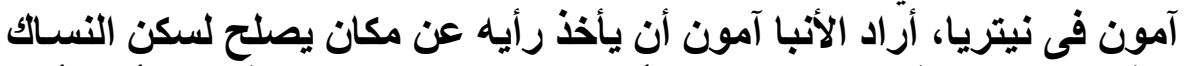

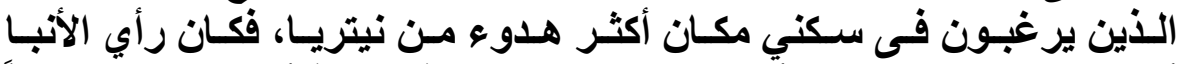

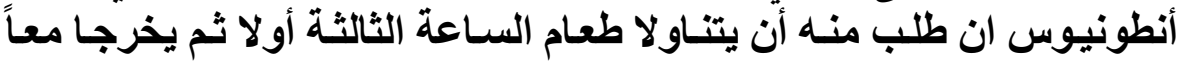

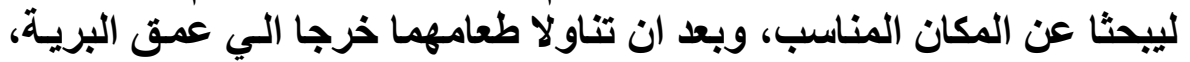

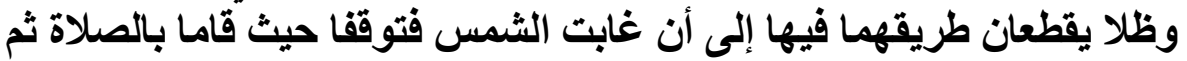

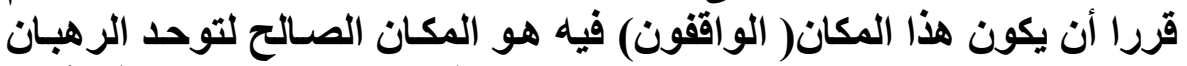

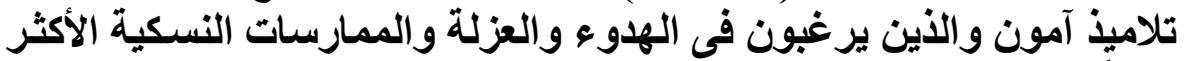

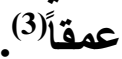

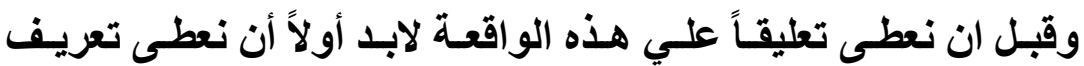

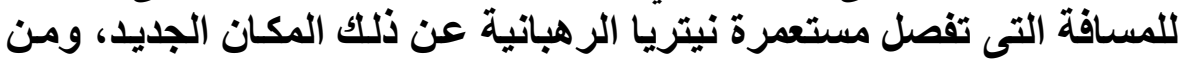

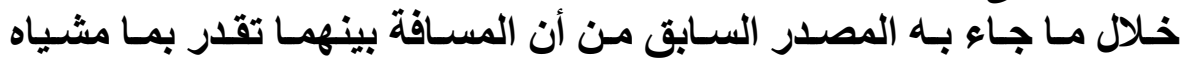

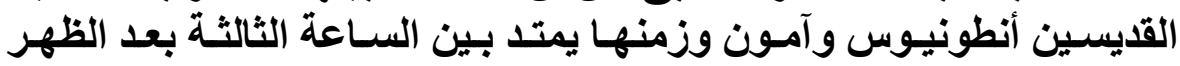

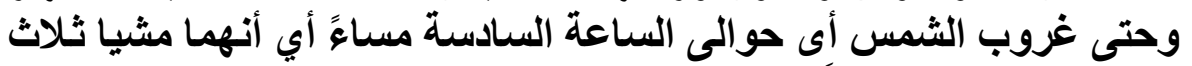

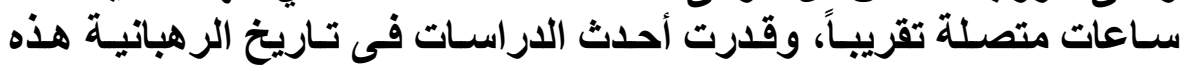

${ }^{(1)}$ Rufinus, Lives of the Desert Fathers, Ch., 22.

${ }^{(2)}$ Pall.Op. Cit., Ch., 8.

${ }^{(3)}$ The Sayings of The Desert Fathers, Antony The Great, 34. 
المسافة بنحو عشرة إلى أثنى عشرة ميلاًا (1)، أى مـا يقرب من ثنلاث عشرة

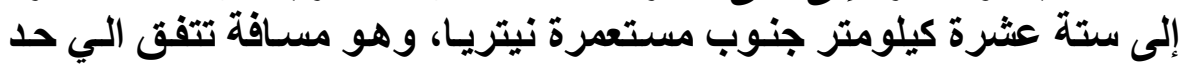

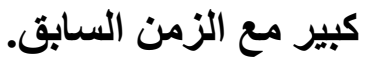

ويضيف المصدر ان القديس انطونيوس رغب في في تحديد هذا المكان

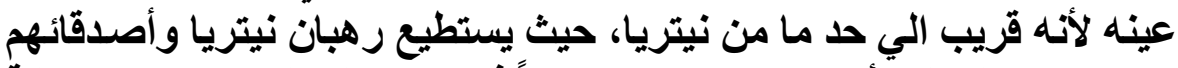

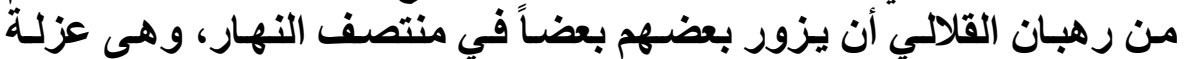

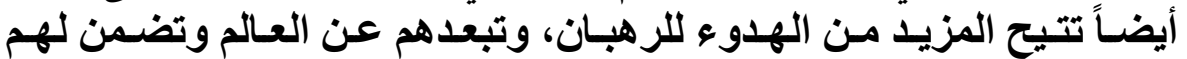

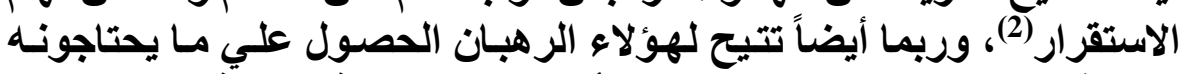
من غذاء ضروري لحياتهم من نيتريا أو حتى من القرية القرئية القرية منها.

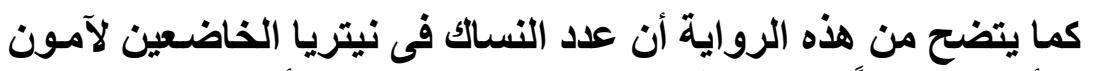

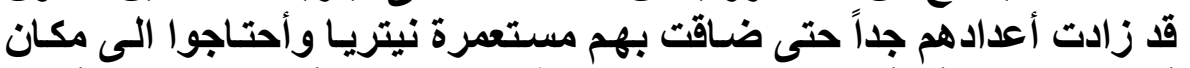

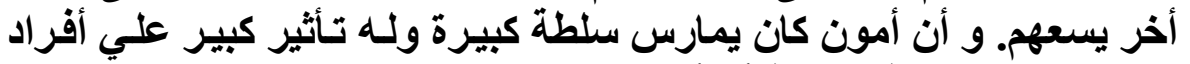

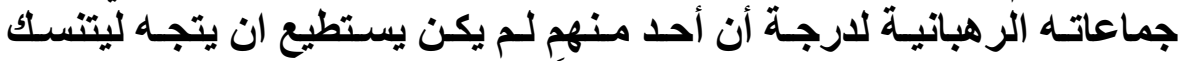

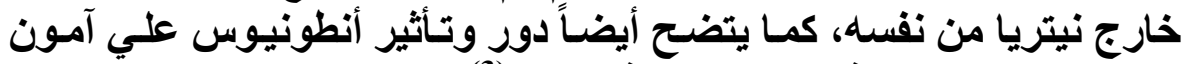

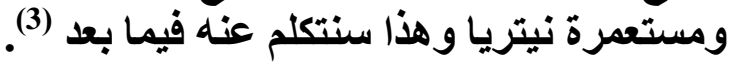

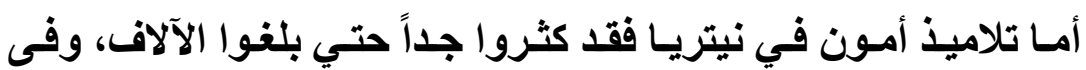

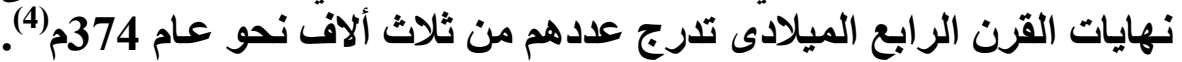
إلى خمسـة آلاف حوالي الئيات

${ }^{(1)}$ Patrich, Op.Cit., p. 11.

${ }^{(2)}$ The Sayings of The Desent Fathers, Anthony The Greal, 34.

(3) 22 - (نظر: ص 21

${ }^{(4)}$ Rufings, History of the Church, Trans.by Philip R., S .J.Amidon ,Oxford,1997, Bood. 2, Ch. 3. 
عام 390م(1)، أما عدد رهبان القلالي فكان يبلغ نحو ستمائه راهب في هذا

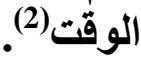

وهنـاك إثـارات فى المصادر عن وجود علاقة بين أمون ومستعمرة

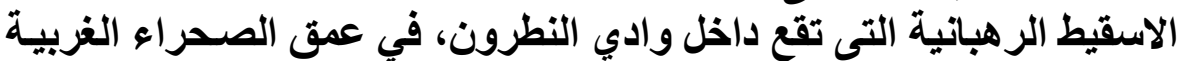

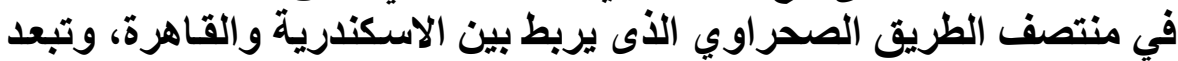

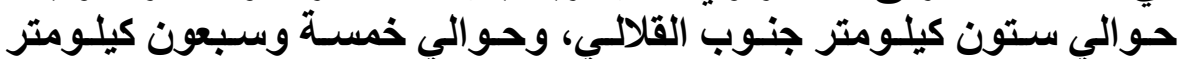
جنوب نتيريان(3).

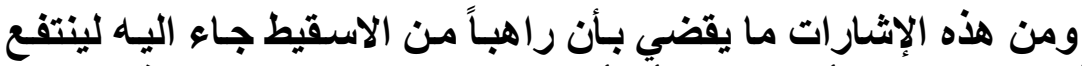

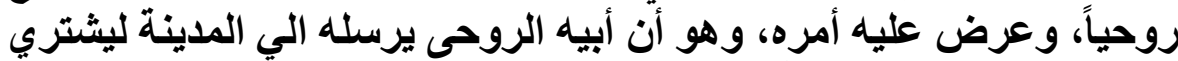

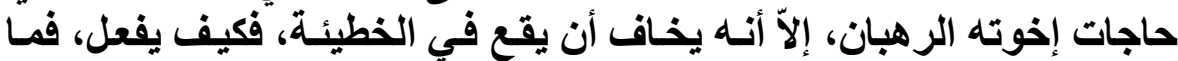

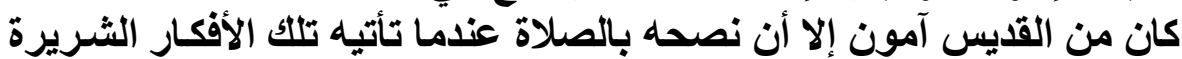

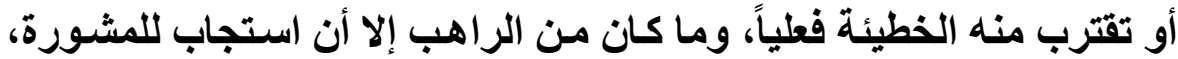

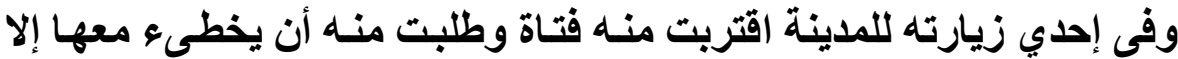

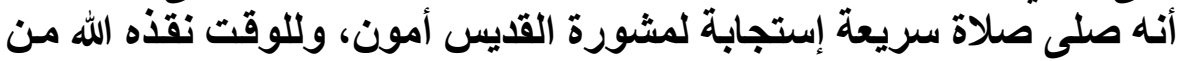

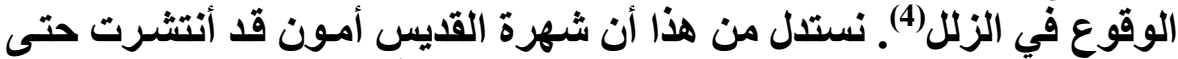

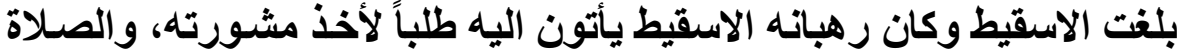

أمسا بالنسبة الـي علاقة آمسون بالأنبـا أنطونيوس أب الرهبانيـة، فكمـا

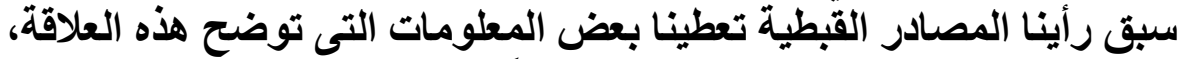

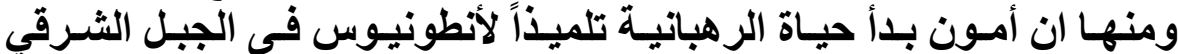

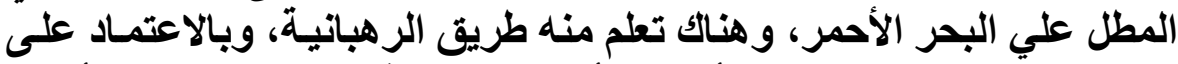

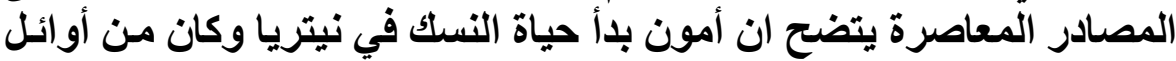

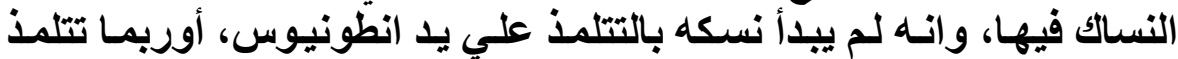

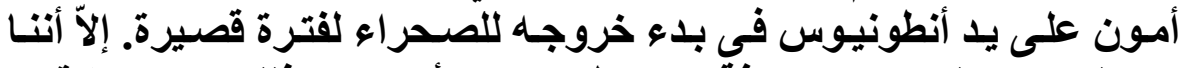
نستلال منها علي وجود معرفة بين انطونيوس وأمون، وكذلك وجود علاقدات

${ }^{(1)}$ Pall., Op. Cit., Ch. 7, 13.

${ }^{(2)}$ Soc., Op. Cit., Book, IV, Ch. 31.

${ }^{(3)}$ Patrich, Op. Cit., p. 12.; Chitty, Op. Cit., p. 17, 33.

${ }^{(4)}$ The Sayings of The Desert Fathers, Amoun of Nitria, 3 
تربط بينهما بإعتبار أنهما شخصان لهمـا أهميتهما في الحركة الرهبانية(1).

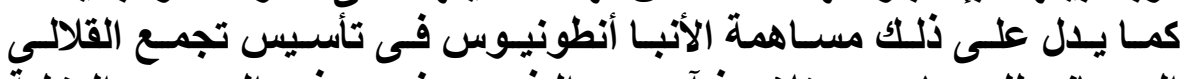

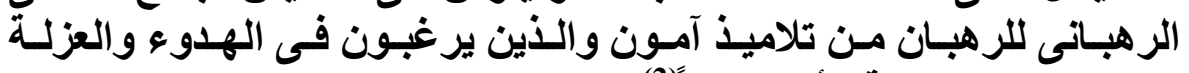

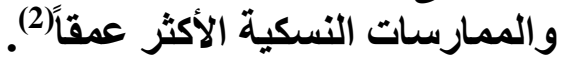

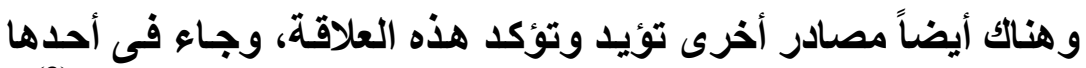

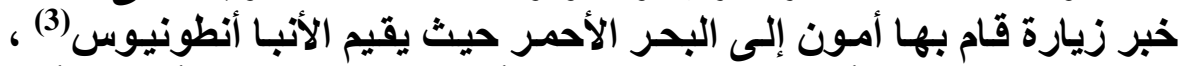

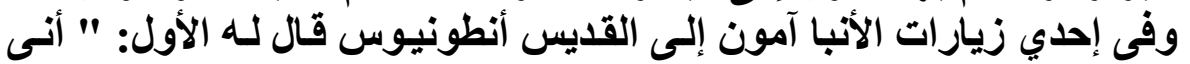

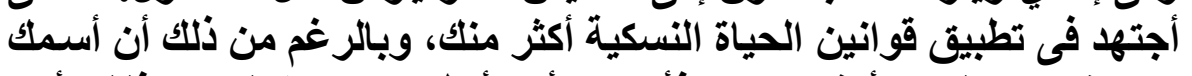

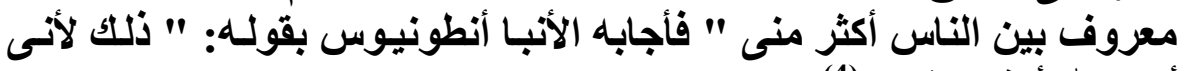

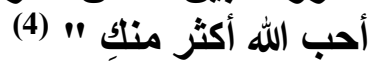

نلاحظ من هذا النص أن آمون كان يعرف انطونيوس وكان يعتاد زيارة

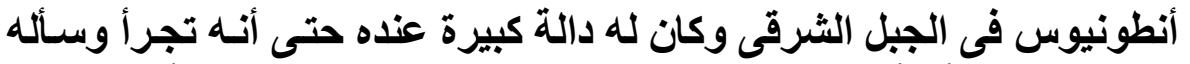

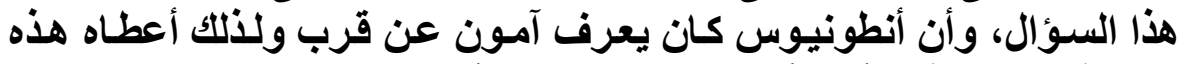

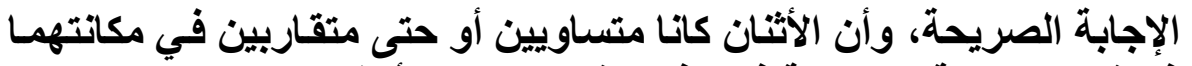

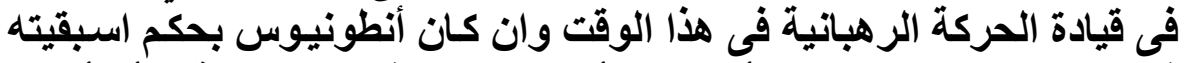

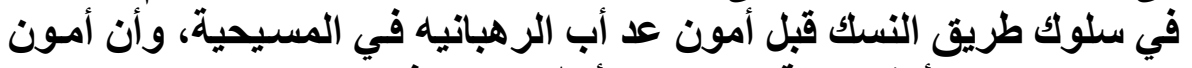

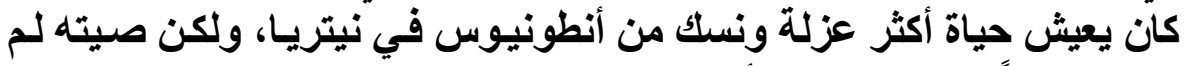
يكن منتشراً بين الناس مثل أنطونيوس.

ومما يذكر أيضاً عن علاقة آمون بأنطونيوس، أن أنطونيوس أرسل

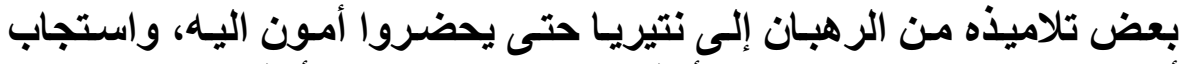

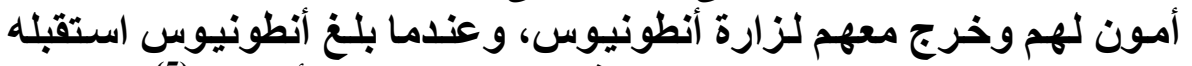

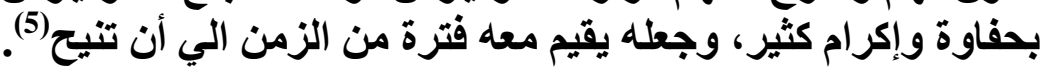

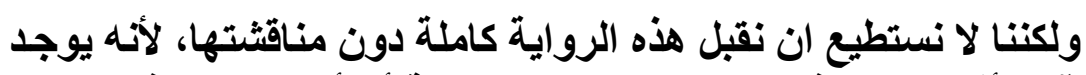

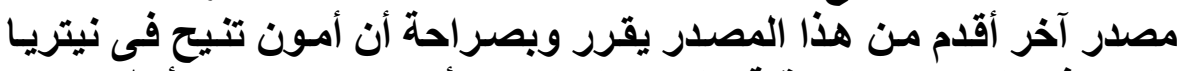

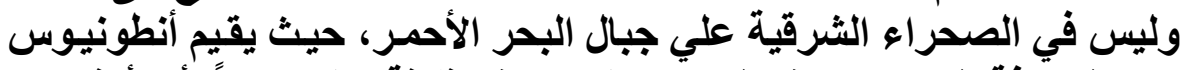

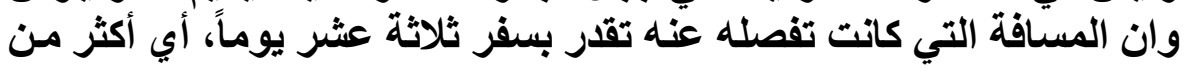

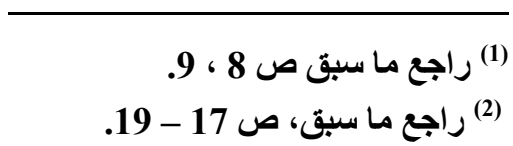

(3) Athanasius, The Life of Antony, Ch. 60.

(4) The Sayings of The Desert Fathers, Amoun of Nitria, 1.

${ }^{(5)}$ Rufinus, Lives of the Desert Fathers., Ch. 22. 
ثلثمائة كيلو متر، وقد جاء رهبان من نيتريا الي انطونيوس بعد ثُلاثين يومـاً

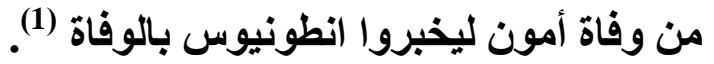

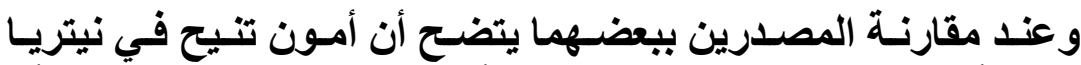

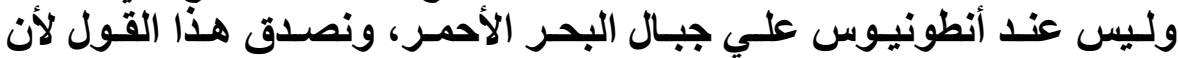

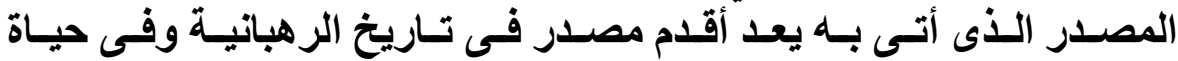

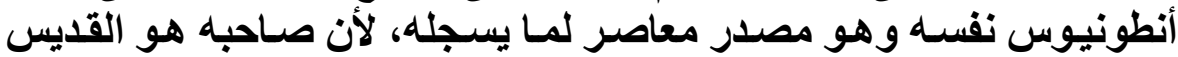

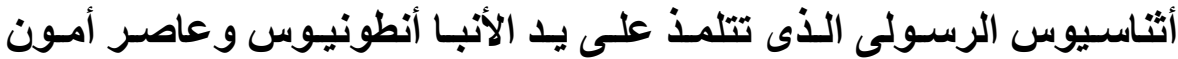

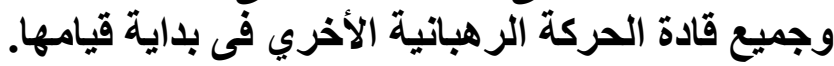

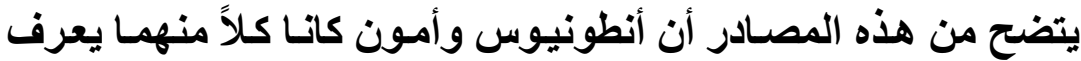

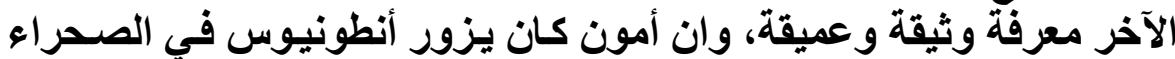

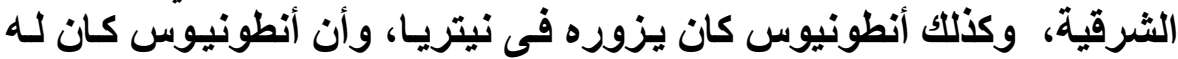

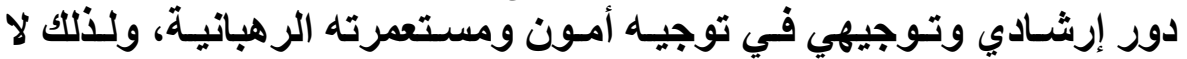

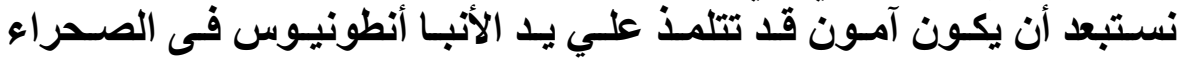
الشرقية فترة قصيرة من الزمن.

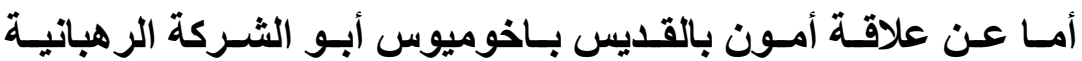

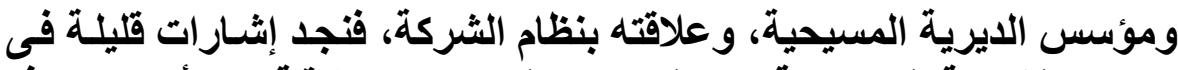

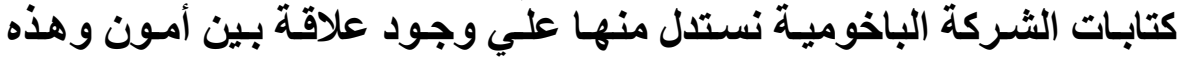

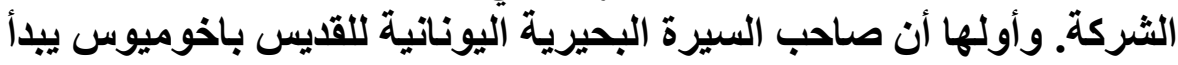

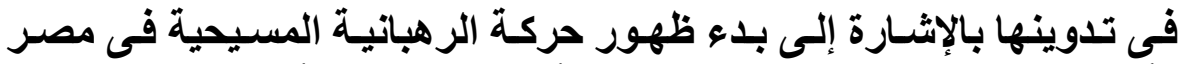

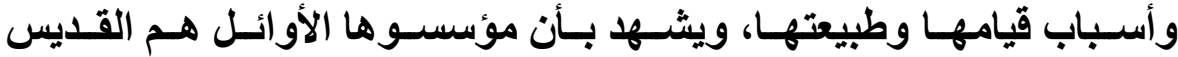

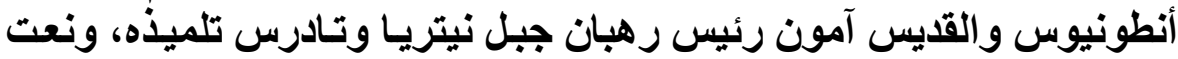

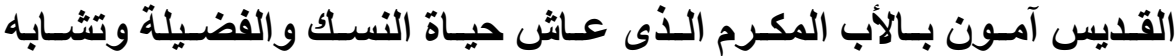

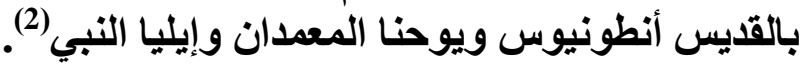

(1) Athanasuis, The Life of Antony, Ch. 60.

(1) The Bohairic Life of Pachonius, Trans. With Introd. By Armand Veilleux, In Pachomian Koinonia, Michigan, 19801983, 3 vol. Vol. 1Ch. 2.; The First Greek Life of Pachomius, Trans. With Intred. By, Armand Veilleux, In (Pach. Koin.), Vol.1, Ch. 2. 
كذلك تكررت هذه الإشـارات مرتين داخل كتابـات الثركة الباخومية،

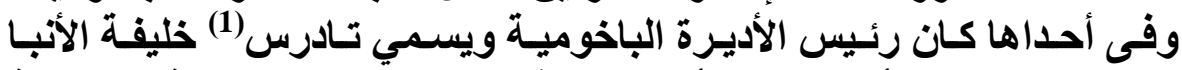

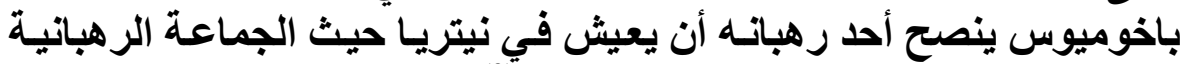

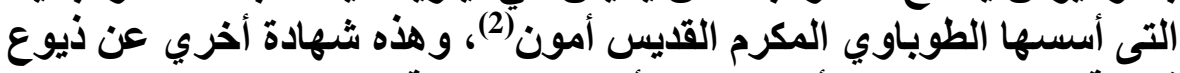

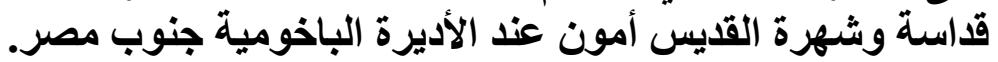

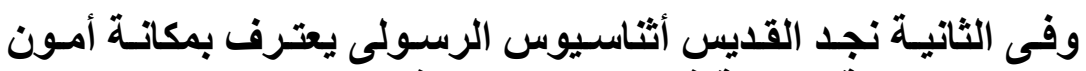

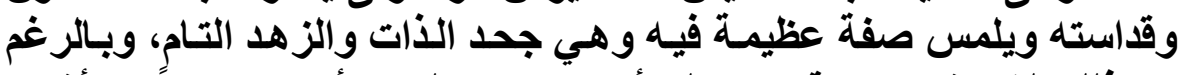

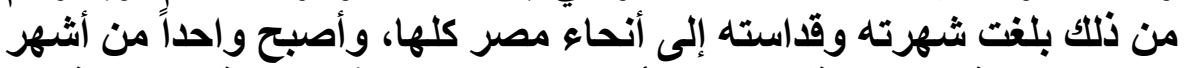

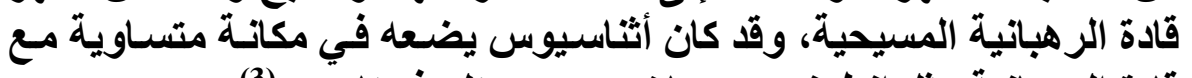

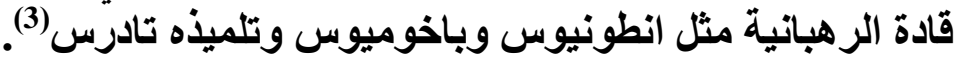

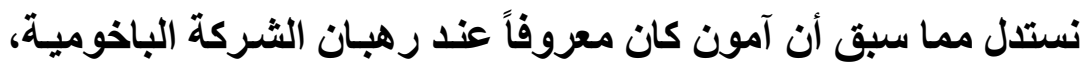

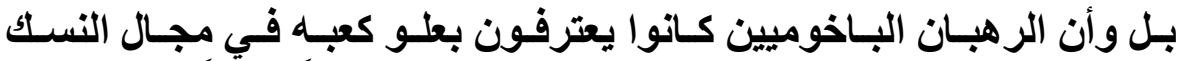

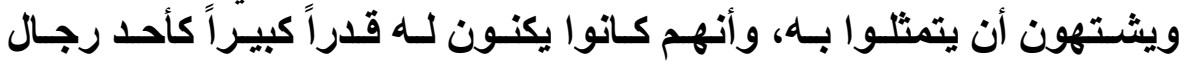

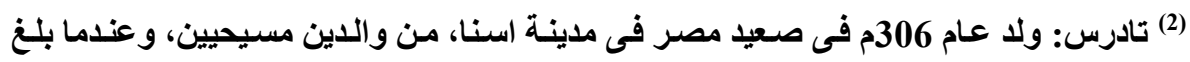

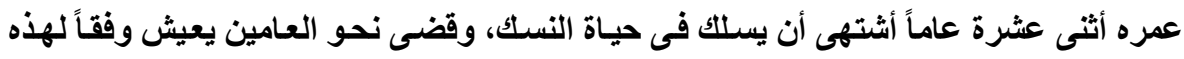

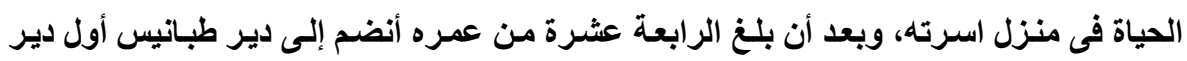

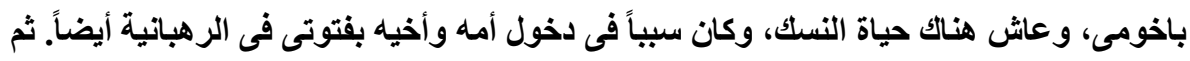

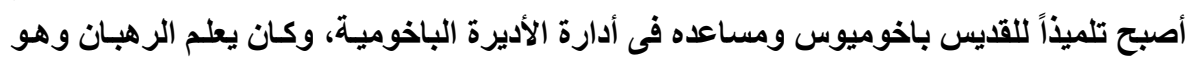

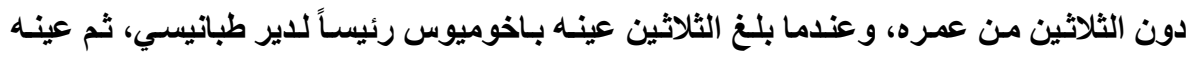

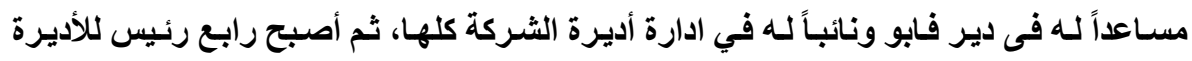

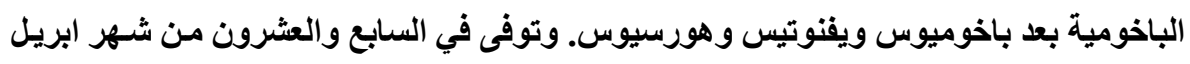

$$
\text { للمزيد من 368م. التفاصيل راجع: باخي }
$$

SBO, Ch. 29 ff, G1., Ch. 33 ff.; Chitty, Op. Cit., p. 21 ff.

ايريس حبيب المصري: قصة الكنيسة القبطية، 9 أجزاء، الجزء الأول، الطبعة السابعة (القاهرة،

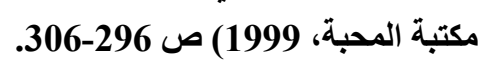

(3) Bishop Ammon, A Letter about the Way of Life of Pachomius and Theodore and about Part of Their Life, Trans. With Introd. By, Armand Veilleux In (Pach. Koin) Vol. 2, Ch. 30.

${ }^{(1)}$ Bishcp Ammon, Op. Cit., Ch, 34. 
الرهبانية الأوائل وأحل مؤسسيها العظماء، ويضعونه مع القديس أنطونيوس

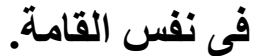

من هذا البحث عن أمون يتضح أن أهم مصدر جاء بـه أخبار عن أمون

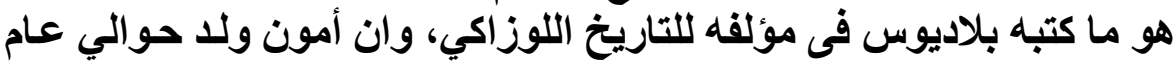

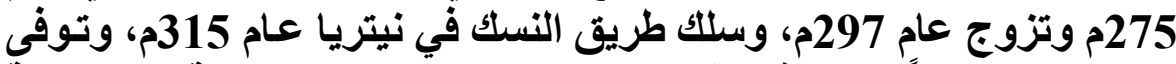

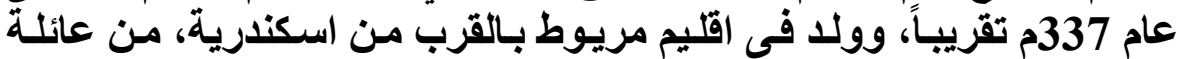

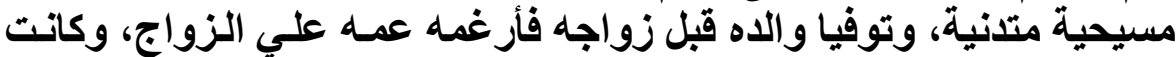

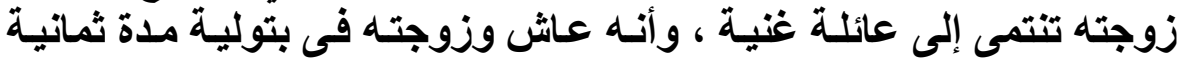

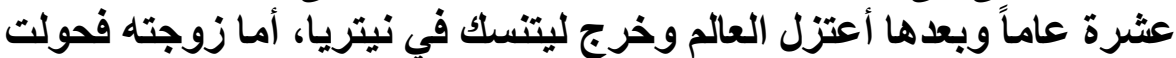

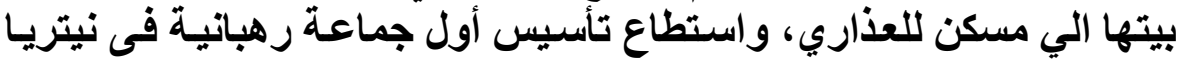

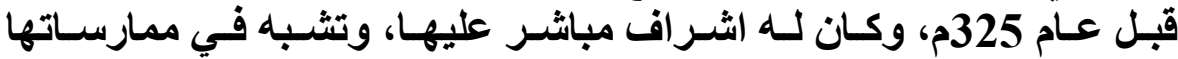

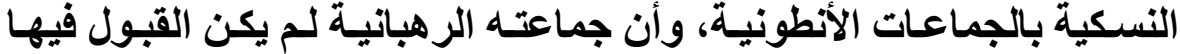

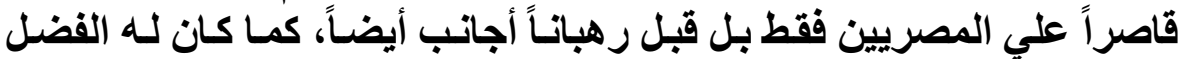

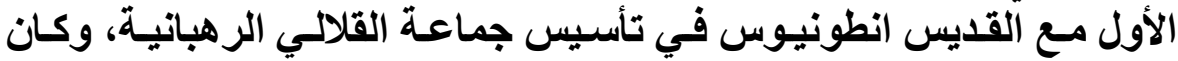

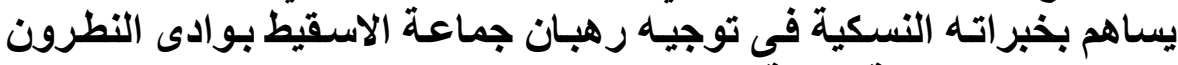
المستعمرة الرهبانية الثالثة بوادي النطرون.

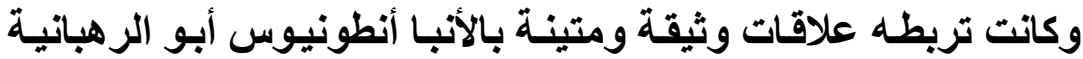

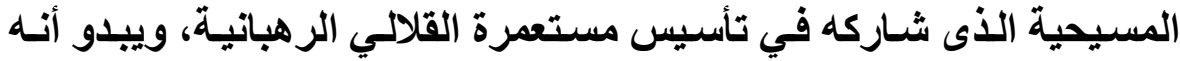

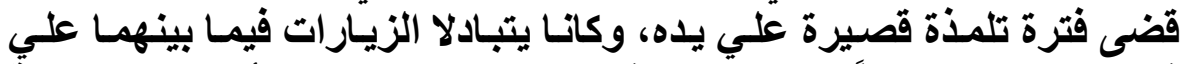

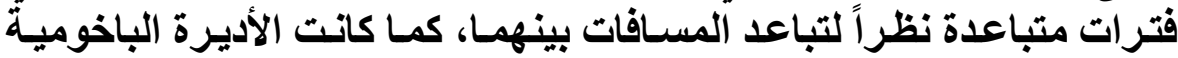

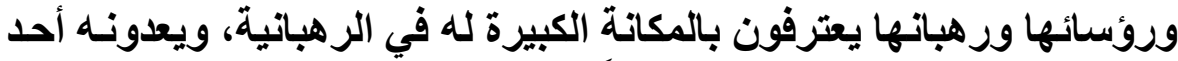

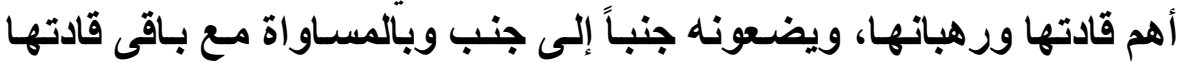

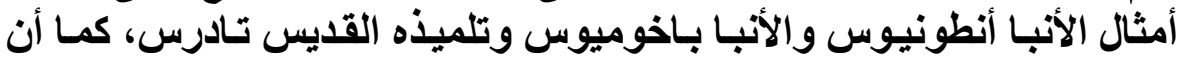

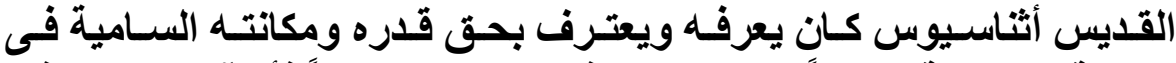

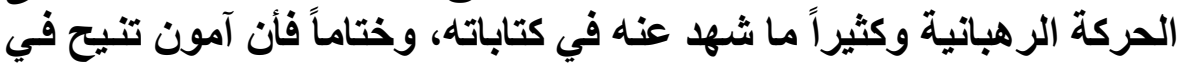

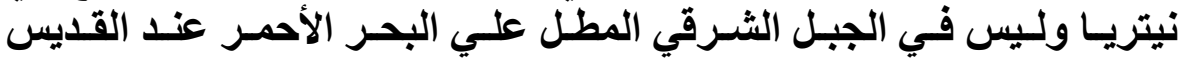
انطونيوس.

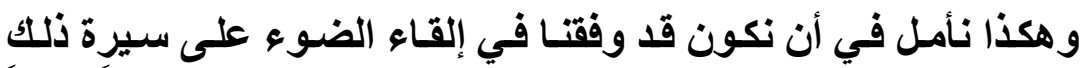

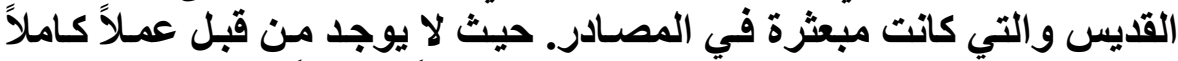
من سيرة ذلك القديس. لذا يُعد ذلكك العمل أول عملاً متكاملاً عن ذلك القديس. 


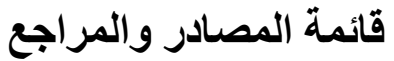

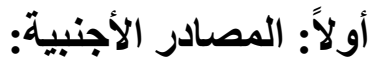

(1) Asanathus, The Life of S. Antony, Trans.With Not.by Archibald Robertson,In:Nicene And Post Nicene Fathers, ed. By Philip Schaff And Henry Wace, New York, 1994.

(2) Bishop Amoun, A Letter about the Way of Life of Pachomius and Theodore and about Part of Their Life, Trans. With Introd. By, Armand Veilleux In (Pachomian Koinonia) 3 vol., Michigan, 1981-1983. Vol. 2, 1982.

(3) Jerom, The Illusterus Men, Trans. With Introd.And Not.by,Ernest cushing Richardson,In(N.P.N.F.) $2^{\text {nd }}$ ser.vol.3.

(4) Palladius, The Lausiac Histery, Trans. And Annot. By Robert T. Meyer. London. 1965.

(5) Rufings, History of the Church, Trans.by Philip R.,S.J. Amidon, Oxford,1997.

(6) ..........., Lives of the Desert Fathers, trans.by, Norman Russell, Introduction by Sister Benedicta,in Monastic Studies Series 4,U.S.A, 1981.

(7) Sayings of The Desert Fathers, Trans. And Foreward by, Benedicta Ward. New York, 1975.

(8) Sozomenus, History Of The church, trans.by, Chester D.Hartranft, in (N.P.N.F.) $2^{\text {nd }}$ ser., Vol. 1.

(9)The Bohairic Life of Pachonius, Trans. With Introd. By Armand Veilleux, In Pachomian Koinonia, 3 vol., Michigan, 1981-1983.

(10) The First Greek Life of Pachomius, Trans. With Intred. By, Armand Veilleux, In (Pach. Koin.) Vol.1. 1981. 


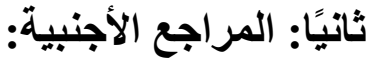

Derwas, J.Chitty,The Desert ACity,Oxford,1966.

H.G. Evelyn White,The Monasteries Of The Wadis n Natrun, 3 vol. NewYork, 1931-1933, Vol, II.

Patrich,j. Joseph, Sabas, Leader of Palestinian Monasticism, A Comparative Study in Eastern Monasticism, Fourth to Seventh Centuries, (Washington, 1995)

R. P. Paul Cheneau. D'Orleans, Les Saintes D'Egypte, 2 vol., Jersalem, 1923, Vol, 1.

W.H. Mackean, Christianity Monasticism In Egypt To The Close Of Fourth Century. , London, 1920.

$$
\text { 1 ثالثًا: المصادر والمراجع العربية: }
$$

2- ايريس حبيب المصري: قصنة الكنيسة القبطية، 9 أجزاء، الجزء الأول،

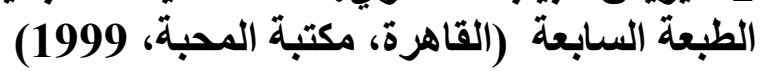

3- متي المسكين، الرهبانية القبطية عن القديس أبو مقار، الطبعة الثبة الثالثة، (الإسكندرية، دار مجلة مارمرقس). 